\title{
Selective oxidation of methyl alpha-D-glucopyranoside with oxygen over supported platinum : kinetic modeling in the presence of deactivation by overoxidation of the catalyst
}

\author{
Citation for published version (APA): \\ Vleeming, J. H., Kuster, B. F. M., \& Marin, G. B. M. M. (1997). Selective oxidation of methyl alpha-D- \\ glucopyranoside with oxygen over supported platinum : kinetic modeling in the presence of deactivation by \\ overoxidation of the catalyst. Industrial and Engineering Chemistry Research, 36(9), 3541-3553. \\ https://doi.org/10.1021/ie9607659
}

DOI:

10.1021/ie9607659

Document status and date:

Published: 01/01/1997

\section{Document Version:}

Publisher's PDF, also known as Version of Record (includes final page, issue and volume numbers)

\section{Please check the document version of this publication:}

- A submitted manuscript is the version of the article upon submission and before peer-review. There can be important differences between the submitted version and the official published version of record. People interested in the research are advised to contact the author for the final version of the publication, or visit the DOI to the publisher's website.

- The final author version and the galley proof are versions of the publication after peer review.

- The final published version features the final layout of the paper including the volume, issue and page numbers.

Link to publication

\footnotetext{
General rights

- You may freely distribute the URL identifying the publication in the public portal. follow below link for the End User Agreement:

www.tue.nl/taverne

Take down policy

If you believe that this document breaches copyright please contact us at:

openaccess@tue.nl

providing details and we will investigate your claim.
}

Copyright and moral rights for the publications made accessible in the public portal are retained by the authors and/or other copyright owners and it is a condition of accessing publications that users recognise and abide by the legal requirements associated with these rights.

- Users may download and print one copy of any publication from the public portal for the purpose of private study or research.

- You may not further distribute the material or use it for any profit-making activity or commercial gain

If the publication is distributed under the terms of Article $25 \mathrm{fa}$ of the Dutch Copyright Act, indicated by the "Taverne" license above, please 


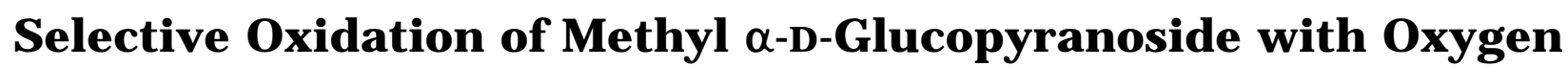 over Supported Platinum: Kinetic Modeling in the Presence of Deactivation by Overoxidation of the Catalyst
}

\author{
J ohannes H. Vleeming, ${ }^{\dagger}$ Ben F. M. Kuster,* and Guy B. Marin ${ }^{\ddagger}$ \\ Laboratorium voor Chemische Technol ogie, Schuit Institute of Catalysis, Eindhoven University of Technol ogy, \\ P.O. Box 513, 5600 MB Eindhoven, The Netherlands
}

\begin{abstract}
A kinetic model is presented, which describes the platinum-catalyzed selective oxidation of methyl $\alpha$-D-glucopyranoside to sodium methyl $\alpha$-D-glucuronate with molecular oxygen in the presence of deactivation by overoxidation. Overoxidation is completely reversible and most adequately described by a reversible transformation of oxygen adatoms into inactive subsurface oxygen. A clear distinction is made between the rapid establishment of the steady-state degree of coverage by the reaction intermediates at the platinum surface and the much slower reversible process of overoxidation. This clear distinction is reflected in the rate equation, which can be written as the product of an initial rate and a deactivation function. The deactivation function is given as a function of the degree of coverage by inactive subsurface oxygen. The rate-determining step in the selective oxidation consists of the reaction between dissociatively chemisorbed oxygen and physisorbed methyl $\alpha$-D-glucopyranoside. The corresponding standard activation entropy and enthal py amount to respectively $-111 \pm 12 \mathrm{~J} \mathrm{~mol}^{-1} \mathrm{~K}^{-1}$ and $51 \pm 4 \mathrm{~kJ} \mathrm{~mol}^{-1}$. The standard reaction entropy for the transformation of oxygen atoms into subsurface oxygen amounts to $-35 \pm 16 \mathrm{~J} \mathrm{~mol}^{-1} \mathrm{~K}^{-1}$ and the standard reaction enthalpy to $-36 \pm 15 \mathrm{~kJ} \mathrm{~mol}^{-1}$.
\end{abstract}

\section{Introduction}

The selective oxidation of alcohols and carbohydrates with molecular oxygen in aqueous media is an industrial and environmental attractive process. The oxidation toward carboxylic acids or ketones can be performed very selectively over a noble metal catalyst, usually platinum or palladium (Heyns and Paulsen, 1962; Van Bekkum, 1991). Starting from renewable resources it offers an important first step toward valuable products, which can for example be applied in detergents, paper, pharmaceutical products, cosmetics, and food ingredients (Röper and Koch, 1988).

The oxidation of a primary alcohol is generally considered to proceed via the oxidative dehydrogenation of the alcohol to the corresponding aldehyde, followed by the selective oxidation of the aldehyde yiel ding the carboxylic acid, which is obtained as the carboxylic anion in alkaline aqueous media:

$$
\begin{gathered}
\mathrm{RCH}_{2} \mathrm{OH}+{ }^{1} / 2 \mathrm{O}_{2} \rightarrow \mathrm{RCHO}+\mathrm{H}_{2} \mathrm{O} \\
\mathrm{RCHO}+{ }^{1} / 2 \mathrm{O}_{2}+\mathrm{OH}^{-} \rightarrow \mathrm{RCOO}^{-}+\mathrm{H}_{2} \mathrm{O} \\
\mathrm{RCH}_{2} \mathrm{OH}+\mathrm{O}_{2}+\mathrm{OH}^{-} \rightarrow \mathrm{RCOO}^{-}+2 \mathrm{H}_{2} \mathrm{O}
\end{gathered}
$$

Catalyst deactivation is often reported (Mallat and Baiker, 1994; Vleeming et al., 1994, 1997) and forms a major drawback for industrial application. Various causes of deactivation are known: poisoning by oxygen (Dirkx and Van der Baan, 1981a,b; Dijkgraaf et al., 1988a,b; Schuurman et al., 1992a; Mallat et al., 1992), deposition of carbonaceous species (Parsons and Vander-

* To whom correspondence should be addressed: telephone, -31 40 2472850; telefax, -31 40 2446653; e-mail, margriet@ chem.tue.nl.

† Present address: Institut Français du Pétrole, BP 3, 69390 Vernaison, France.

$\ddagger$ Present address: Laboratorium voor Petrochemische Techniek, Universiteit van Gent, Krijgslaan 281, B-9000 Bel gium.
Noot, 1988; Brönniman et al., 1994; Vleeming et al., 1994, 1997; Abbadi and Van Bekkum, 1995), metal particle growth (Schuurman et al., 1992a; Vleeming et al., 1997) and metal leaching (Schuurman et al., 1992a; Brönniman et al., 1994; Vleeming et al., 1994, 1997).

Deactivation by so-called overoxidation or oxygen poisoning, has obtained most attention. Overoxidation can be ascribed to the strong chemisorption of oxygen or oxygen-containing species at the metal surface (Peukert et al., 1984; Schuurman et al., 1992a; Mallat and Baiker, 1994). Deactivation by overoxidation can be easily recovered upon reduction of the catalyst, which can often be applied in-situ at mild conditions (Dijkgraaf et al., 1988b; Schuurman et al., 1992a; Vleeming et al., 1994, 1997).

The occurrence of overoxidation depends on the balance between the active metal surface coverage with oxygen and alcohol. A large potential oxygen supply rate or a low potential reducing rate by the al cohol may lead to over oxidation (Schuurman et al ., 1992a; Vleeming et al., 1994). In the opposite situation overoxidation may not take place, but the active metal surface area is more likely to suffer from poisoning through site coverage by carbonaceous products (Parsons and VanderNoot, 1988), especially when the catalyst is prereduced by the alcohol (Mallat et al., 1993; Besson et al., 1994).

In literature some examples of kinetic models that account for deactivation by overoxidation during alcohol or carbohydrate oxidation are presented. Dirkx and Van der Baan $(1981 a, b)$ accounted for the observed deactivation during the oxidation of gl ucose or gluconic acid by an activity factor, which was a function of the conversion. The presence of three types of adsorbed oxygen, $\mathrm{PtO}, \mathrm{PtO}_{2}$, and molecular oxygen, was assumed. Dijkgraaf et al. (1988a) used an exponential deactivation function of time on stream to account for the deactivation during the oxidation of D-gluconate. Khan et al. (1983) also described the effect of overoxidation by a first-order deactivation process. Recently, J elemensky et al. $(1996,1997)$ constructed a kinetic model for the 
description of multiple steady-state data and relaxation processes for the selective oxidation of ethanol which accounted for overoxidation by the transformation of surface oxygen species into subsurface oxygen.

The present paper concerns the investigation of overoxidation for the oxidation of methyl $\alpha$-D-glucopyranoside to methyl $\alpha$-D-glucuronate by the development of a kinetic model that quantitatively describes the observed data in the presence of deactivation by overoxidation. The model is aimed not only at describing the observed data but also at providing a better understanding of the surface chemistry during aqueous phase alcohol oxidation, especially concerning the process of overoxidation. Hence, concern was taken to avoid mass transport limitations, i.e., to obtain intrinsic kinetic data, and to prevent a decrease of the active platinum surface area by other deactivation processes, such as deposition of carbonaceous species, platinum particle growth, and leaching.

\section{Experimental Section}

Catalyst. A 3.3 wt \% Pt/graphite catalyst was used, prepared according to the procedure of Richard and Gallezot (1987). Details of this procedure are described elsewhere (Vleeming et al., 1997). The diameter of $95 \%$ of the graphite powder particles was smaller than 30 $\mu \mathrm{m}$. The BET surface area amounted to $1.02 \times 10^{5} \mathrm{~m}^{2}$ $\mathrm{kg}_{\mathrm{cat}}{ }^{-1}$. Before the start of each experiment $0.7 \mathrm{~g}$ of dry fresh catalyst was prereduced in $0.35 \mathrm{~L}$ water at $363 \mathrm{~K}$ for $30 \mathrm{~min}$ in a hydrogen flow. The fraction exposed measured with CO chemisorption was 0.43 after prereduction, and the surface area averaged platinum particle diameter, obtained with transmission electron microscopy (TEM), amounted to $1.90 \pm 0.05 \mathrm{~nm}$. The corresponding amount of surface atoms, $L_{t}$, amounts to $0.073 \mathrm{~mol} \mathrm{~kg}_{\mathrm{cat}^{-1}}{ }^{-1}$ and does not change under the conditions of the present work. Hence, catalyst deactivation during methyl $\alpha$-D-glucopyranoside oxidation due to particle growth, metal leaching, and deposition of carbonaceous species can be neglected.

Equipment, Procedure, and Conditions. The experiments were performed in a $0.7 \times 10^{-3} \mathrm{~m}^{3}$ continuous three-phase slurry reactor (CSTR). The setup and procedures are described elsewhere (Vleeming et al., 1997). The experiments were performed under welldefined conditions by control of the reactor temperature, pressure, reaction volume, and gas and liquid composition. The control of the latter was achieved by adapting the liquid feed flow rate to the rate of production of methyl $\alpha$-D-glucuronate by a feedback PID-control (E urotherm 940D) based on the $\mathrm{pH}$ measurement of the reaction mixture. In this way the concentrations of methyl $\alpha$-D-glucopyranoside, methyl $\alpha$-D-al dehydoglucopyranoside, and methyl $\alpha$-D-glucuronate are kept constant despite catalyst deactivation, provided that deactivation does not result in selectivity changes. This was verified experimentally. The investigated range of reaction conditions is given in Table 1 .

Before the start of the oxidation reaction the catalyst was prereduced in $0.35 \times 10^{-3} \mathrm{~m}^{3}$ water at $363 \mathrm{~K}$ for $30 \mathrm{~min}$ in a hydrogen flow. Next, the reactor was cooled down under a nitrogen flow to the reaction temperature, and the water was removed. A solution with the appropriate concentrations of methyl $\alpha$-D-glucopyranoside, methyl $\alpha$-D-aldehydoglucopyranoside, and sodium methyl $\alpha$-D-glucuronate was added, which was previously prepared by a separate batch reaction. The reaction was started at a stirring rate of $25 \mathrm{~s}^{-1}$ by
Table 1. Investigated Range of Reaction Conditions

\begin{tabular}{ll}
\hline \multicolumn{1}{c}{ condition } & \multicolumn{1}{c}{ range } \\
\hline concentration methyl $\alpha$-D-glucopyranoside $\left(\mathrm{mol} \mathrm{m}^{-3}\right)$ & $11-427$ \\
concentration methyl & $0.2-6.6$ \\
$\quad \alpha$-D-aldehydoglucopyranoside $\left(\mathrm{mol} \mathrm{m}^{-3}\right)$ & \\
concentration methyl $\alpha$-D-glucuronate $\left(\mathrm{mol} \mathrm{m}^{-3}\right)$ & $1.5-41$ \\
oxygen partial pressure $(\mathrm{kPa})$ & $10-100$ \\
total pressure $(\mathrm{kPa})$ & 100 \\
pH & $8-10$ \\
temperature $(\mathrm{K})$ & $303-333$ \\
catalyst concentration $\left(\mathrm{kg} \mathrm{m}^{-3}\right)$ & $1-4$ \\
reaction volume $\left(10^{-3} \mathrm{~m}^{3}\right)$ & 0.35 \\
conversion of methyl $\alpha-\mathrm{D}-\mathrm{glucopyranoside}$ & $0.03-0.47$ \\
conversion of oxygen & $0.02-0.2$
\end{tabular}

replacing the nitrogen flow by a flow with the appropriate partial pressure of oxygen.

Each experiment consisted of three consecutive oxidation runs of $10000 \mathrm{~s}$. Between two consecutive oxidation runs the catalyst was reduced by introducing nitrogen for 1000 s resulting in a complete recovery of the catalyst activity. F or each experiment $40\left(t, R_{w}\right)$ data points were used for regression in the time interval between 0 and $10000 \mathrm{~s}$ by taking the average of the three consecutive oxidation runs.

All rates are expressed as the specific rate of consumption of methyl $\alpha$-D-gl ucopyranoside, which is calculated from the experimental data according to

$$
R_{w, M G P}(t)=\frac{F_{v, L}(t)\left(C_{M G P}{ }^{0}-C_{M G P}\right)}{W_{c a t}}
$$

It was verified by calculations that the experiments were not significantly influenced by mass and heat transport limitations. Experimentally the absence of gas-liquid oxygen transfer limitation was confirmed by measurement of the aqueous phase oxygen concentration.

The reaction mixtures were analyzed by on- and offline high-performance liquid chromatography (HPLC) analysis. On-line HPLC was performed on a $280 \times 4.6$ $\mathrm{mm}$ i.d. Lichroma SS tube packed with a cationexchange resin (Benson BC-X8) having sulfonic acid groups. Refractive index detection was used. The column was brought in the $\mathrm{H}^{+}$-form and was frequently regenerated by pumping overnight with a $25 \mathrm{~mol} \mathrm{~m}^{-3}$ $\mathrm{H}_{2} \mathrm{SO}_{4}$ solution in water at $343 \mathrm{~K}$ at a flow rate of 0.75

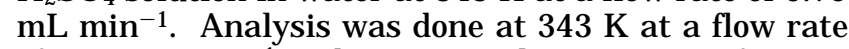
of $0.25 \mathrm{~mL} \mathrm{~min}^{-1}$ with water as eluent. Quantification was performed using external standard solutions. It was assumed that the molar response for methyl $\alpha-D-$ al dehydoglucopyranosi de is equal to that of methyl $\alpha$-Dglucopyranoside, because the refractive index is proportional to the mass of a molecule. It was verified that side products did not interfere. Off-line HPLC analysis occurred according to the procedures described elsewhere (Schuurman et al., 1992a).

Open-circuit catalyst potential measurements were performed on platinum foil in a continuous electrochemical cell, described by J elemensky et al. (1997), or by measurement of the potential of gold or platinum wire brought in contact with the catalyst slurry versus an Ag/AgCl reference electrode (Van Dam et al., 1990; Mallat and Baiker, 1995). All potentials are referred to the reversible hydrogen electrode (RHE).

Parameter Estimation and Model Discrimination. The set of data that was used for regression analysis consisted of 24 experiments. The regression analysis was performed, using a single response Mar- 
quardt algorithm (1963), obtaining maximum likelihood parameter estimates $b$ by minimization of the residual sum of squares, SSR:

$$
\operatorname{SSR}(b)=\sum_{i=1}^{n_{\text {obs }}}\left[R_{w, i}-\hat{R}_{w, i}\right]^{2} \rightarrow \text { MINIMUM }
$$

in which $\mathrm{n}_{\mathrm{obs}}$ is the number of experimental data points, $R_{w, i}$ is the observed and $\hat{R}_{w, i}$ the calculated specific rate of consumption of methyl $\alpha$-D-glucopyranoside. $\hat{R}_{w}$ can be written according to

$$
\hat{\mathrm{R}}_{\mathrm{w}}(\mathrm{t})=\hat{\mathrm{R}}_{\mathrm{w}}{ }^{0} \varphi_{\text {Oinact }}
$$

when the deactivation is separable from the main reaction (Froment and Bischoff, 1990). $\hat{\mathrm{R}}_{\mathrm{w}}{ }^{0}$ is the socalled initial rate, i.e., the steady-state rate in the absence of deactivation, and $\varphi_{\text {oinact }}$ is a deactivation function, which is a function of the degree of coverage by inactive oxygen, $\theta_{\text {oinact. }}$. The latter follows from the corresponding mass balance:

$$
\mathrm{d} \theta_{\text {Oinact }} / \mathrm{dt}=\mathrm{r}_{\text {Oinact }}
$$

In view of the prereduction or reduction between two consecutive oxidation runs the initial condition is given as:

$$
\theta_{\text {Oinact }}=0 \text { at } \mathrm{t}=0
$$

The equations are solved numerically with a RungeKutta routine (D02E BF, NAG Fortran Library).

The calculation of the F-ratio, indicating the significance of the gl obal regression, and the confidence limits for the parameter estimates are described elsewhere (Froment and Bisschof, 1990; Van den Tillaart et al., 1994).

The simultaneous estimation of standard activation entropies, $\Delta^{\# S^{0}}$, and enthal pies, $\Delta^{\#} \mathrm{H}^{0}$, or standard reaction entropies, $\Delta \mathrm{S}^{0}$, and enthal pies, $\Delta \mathrm{H}^{0}$, was performed by the reparameterized expressions (Kittrell, 1970) for the rate coefficients, $k$, derived according to the transition state theory (Laidler, 1987) and the equilibrium constants, K, which are written according to:

$$
\begin{gathered}
\mathrm{k}=\frac{\mathrm{RT}_{\mathrm{avg}}}{\mathrm{N}_{\mathrm{a}} \mathrm{h}} \exp \left(\frac{\Delta^{\#} \mathrm{~S}^{0}}{\mathrm{R}}-\frac{\Delta^{*} \mathrm{H}^{0}}{\mathrm{RT} \mathrm{T}_{\mathrm{avg}}}\right) \exp \left(-\frac{\Delta^{*} \mathrm{H}^{0}}{\mathrm{R}}\left(\frac{1}{\mathrm{~T}}-\frac{1}{\mathrm{~T}_{\text {avg }}}\right)\right) \\
\mathrm{K}=\exp \left(\frac{\Delta \mathrm{S}^{0}}{\mathrm{R}}-\frac{\Delta \mathrm{H}^{0}}{\mathrm{RT} \mathrm{T}_{\text {avg }}}\right) \exp \left(-\frac{\left.\Delta \mathrm{H}^{0}\left(\frac{1}{\mathrm{R}}-\frac{1}{\mathrm{~T}_{\text {avg }}}\right)\right)}{\text { (7) }}\right.
\end{gathered}
$$

in which $T_{\text {avg, }}$ the average temperature, was taken as $318 \mathrm{~K}$. Standard conditions refer to $1 \mathrm{~mol} \mathrm{~m}^{-3}$ and $\theta=$ 0.5 (Everett, 1950).

\section{Nature of Overoxidation Phenomena}

A typical result of an experiment for the oxidation of methyl $\alpha$-D-glucopyranoside in a CSTR is shown in Figure 1 . The rate of consumption of methyl $\alpha-D$ glucopyranoside decreases in $10000 \mathrm{~s}$ to about $20 \%$ of the initial rate as indicated in Figure 1a. Next, the catalyst was reduced in-situ for $1000 \mathrm{~s}$ by replacement of oxygen through nitrogen, allowing oxygen to react with methyl $\alpha$-D-glucopyranoside. After that, the oxidation was continued and a complete recovery of the catalyst activity was observed. This complete recovery

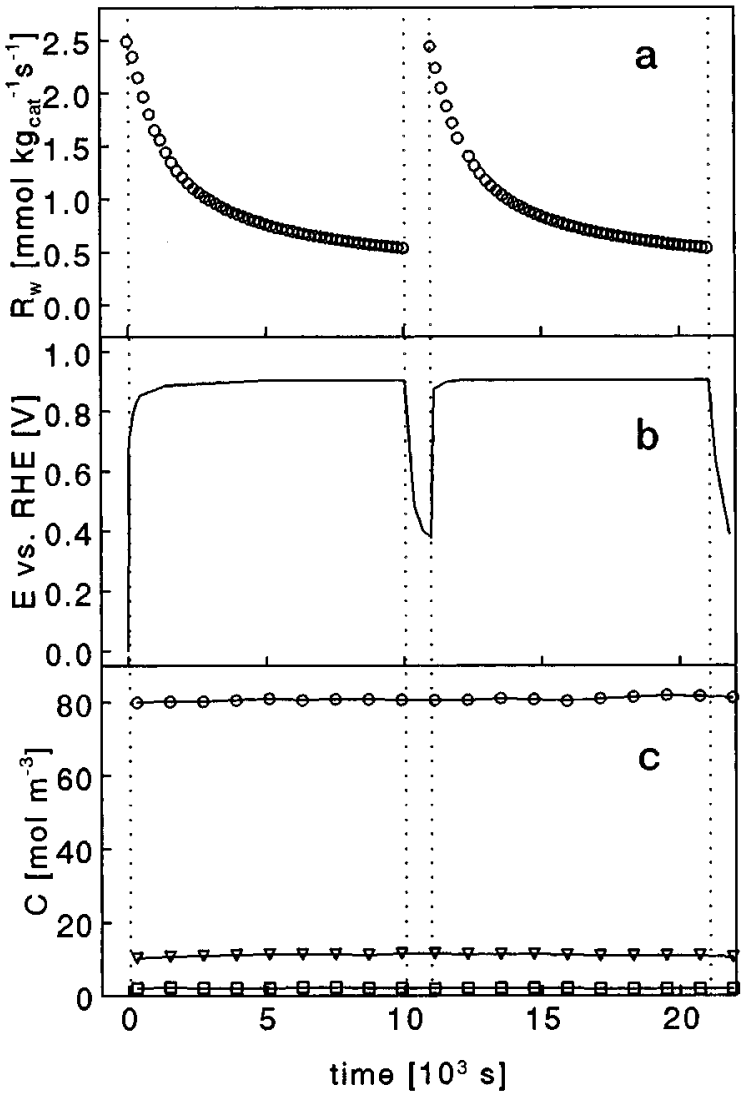

Figure 1. Typical result of an experiment for the oxidation of methyl $\alpha$-D-glucopyranoside with $\mathrm{O}_{2}$ over a 3.3 wt \% Pt/graphite catalyst in a CSTR: (a) specific rate of consumption of methyl $\alpha$-Dglucopyranoside; (b) in-situ open-circuit catalyst potential; (c) concentration of $(O)$ methyl $\alpha$-D-glucopyranoside, $(\square)$ methyl $\alpha$-Daldehydoglucopyranoside, and $(\nabla)$ methyl $\alpha$-D-glucuronate. At $\mathrm{t}=$ 10000 and $21000 \mathrm{~s}$ oxygen in the feed was replaced by nitrogen for $1000 \mathrm{~s}$. Conditions were as follows: $\mathrm{pH}=8.0 ; \mathrm{T}=323 \mathrm{~K} ; \mathrm{p}_{\mathrm{O}_{2}}{ }^{0}$ $=40 \mathrm{kPa} ; \mathrm{C}_{\mathrm{cat}}=2 \mathrm{~kg} \mathrm{~m}^{-3}$.

was observed for all experiments. Hence, irreversible catalyst deactivation can be ruled out, which was confirmed by the absence of catalyst modifications in TEM and CO chemisorption measurements of used catalysts.

The observed decrease of the rate in $10000 \mathrm{~s}$ cannot be due to changes in concentration, because the concentration of methyl $\alpha$-D-glucopyranoside, methyl $\alpha$-Daldehydoglucopyranoside, and methyl $\alpha$-D-glucuronate are constant as shown in Figure 1c. Apparently, the simultaneous and proportional adjustment of theliquid feed flow rate of methyl $\alpha$-D-gl ucopyranoside and sodium hydroxide with deactivation works properly and deactivation does not result in selectivity changes.

The deactivation coincides with an increase of the catalyst potential. Figure $1 b$ shows the open-circuit catalyst potential of the graphite-supported platinum catalyst, which was measured in-situ. The results were confirmed by electrochemical measurements in a continuous operated electrochemical cell at comparable reaction conditions. Starting from a reduced catalyst the potential instantly increases to a potential larger than $0.8 \mathrm{~V}$ vs the reversible hydrogen el ectrode (RHE). During oxidation the potential slowly increases to about $0.9 \mathrm{~V}$ vs RHE, which indicates that during oxidation the platinum surface is mainly covered by oxygen species, since a half-covered PtO surface is reached at about 0.7 $\checkmark$ and a monolayer of oxygen species is reached at 1.0 V (Peukert et al., 1984; De Bruijn, 1996). Adsorbed oxygen species may be transformed into less active or 
inactive oxygen species (Lauterbach et al., 1994; J elemensky et al., 1996). The creation of these inactive oxygen species will also result in a decrease of the catalyst activity but may not coincide with an increase of the measured catalyst potential (J elemensky et al., 1997).

When after an oxidation period of $10000 \mathrm{~s}$ oxygen is replaced by nitrogen, the potential decreases to $0.4 \mathrm{~V}$, as indicated in Figure $1 \mathrm{~b}$. This is due to reduction of the platinum surface through reaction of methyl $\alpha-D-$ glucopyranoside with adsorbed oxygen. After the oxidation is resumed, the catalyst potential during the second oxidation run is equal to that during the first run at equal time of oxidation.

The so-called intrinsic relaxation time required for the establishment of a steady state after changing reaction conditions would, according to Temkin (1976), amount to $25 \mathrm{~s}$ at an estimated steady-state rate of $1 \mathrm{mmol}$ $\mathrm{kg}_{\text {cat }}{ }^{-1} \mathrm{~s}^{-1}$. This is in agreement with the initial fast increase of the catalyst potential shown in Figure 1b. It should be noted that the time before a steady-state aqueous phase oxygen concentration is reached amounts to $300 \mathrm{~s}$, because at a reactor gas volume of $0.35 \times 10^{3}$ $\mathrm{m}^{3}$ and a gas feed flow rate of $1.4 \times 10^{-4} \mathrm{~mol} \mathrm{~s}^{-1}(200$ $\mathrm{NmL} \mathrm{min}^{-1}$ ) the ratio of the oxygen concentration and its steady-state value exceeds 0.95 after $300 \mathrm{~s}$. However, this only has a limited effect on the establishment of the initial oxygen coverage since the dependence of the reaction rate on the oxygen concentration is very limited (Schuurman et al., 1992b). But, even if the intrinsic relaxation time is taken as $300 \mathrm{~s}$, the time scale of overoxidation differs by two orders of magnitude and, hence, should be considered as an extrinsic or side relaxation process.

The conclusion of Mallat and Baiker (1994), that overoxidation is the result of deactivation rather than its cause, cannot explain the above results. According to these authors deactivation is caused by poisoning by side products during prereduction or reaction (Mallat et al., 1993; Brönnimann et al. 1994). Their explanation holds when oxygen transport limitation occurs. Indeed, in such a situation deposition of carbonaceous species will cause a decrease of the fractional coverage of the alcohol relative to the fractional coverage of oxygen, resulting in overoxidation. Hence, site poisoning will not affect the rate of oxygen reduction but only lead to a decrease of the rate of alcohol dehydrogenation. F urthermore, the removal of these carbonaceous species from the active metal surface would necessitate a high potential, which also results in overoxidation (Mallat and Baiker 1994; Brönnimann et al., 1994). In the present work, however, none of the data were significantly influenced by mass and heat transport limitations and no irreversible site coverage is observed. Therefore, it is highly unlikely that overoxidation, which was observed for all experiments, is caused by deactivation due to deposition of carbonaceous species.

Although the open-circuit potential measurements of the catalyst indicate a gradual increase of the oxygen coverage (Peukert et al., 1984), the oxygen coverage cannot directly be calculated from the catalyst potential. This is due to the uncertainty about the oxygen species involved and their contribution to the overall opencircuit catalyst potential (J elemensky et al., 1997). Hence, the in-situ open-circuit potential as such cannot be used to measure quantitatively the oxygen coverage and describe the rate of consumption of methyl $\alpha-D-$ glucopyranoside as a function of this coverage.

\section{Effect of the Reaction Conditions}

Figure 2 shows the rate of consumption of methyl $\alpha-D-$ glucopyranoside as a function of the oxygen partial pressure and the methyl $\alpha$-D-glucopyranoside and sodium methyl $\alpha$-D-glucuronate concentration at $\mathrm{pH}=8.0$ and $323 \mathrm{~K}$. F or each experiment data points are shown at $\mathrm{t}=0,1000$ and $10000 \mathrm{~s}$.

The dependence of the initial rate on the oxygen partial pressure is rather limited (Figure 2a). This is even more clear for the data at $\mathrm{pH}=10$ (not shown). The rate of consumption of methyl $\alpha$-D-gl ucopyranoside increases with increasing concentration of methyl $\alpha-D-$ glucopyranoside as shown in Figure $2 b$ but levels off at higher methyl $\alpha$-D-glucopyranoside concentration. An increase of the sodium methyl $\alpha$-D-glucuronate concentration leads to a decrease of the rate (F igure $2 c)$, which can be due to site coverage by methyl $\alpha$-D-glucuronic acid or side products. The combined effect of methyl $\alpha$-D-glucopyranoside and sodium methyl $\alpha$-D-glucuronate is illustrated in Figure $2 d$, where the concentrations of both are proportionally increased; i.e., a constant conversion level is maintained. The increase of the rate due to a higher methyl $\alpha$-D-gl ucopyranoside concentration is compensated by a decrease caused by a higher product concentration.

The effect of the $\mathrm{pH}$ was studied in a small $\mathrm{pH}$ range, because in more acidic media poisoning by acid reaction products is expected (Abbadi and Van Bekkum, 1995) and at higher $\mathrm{pH}$ noncatalytic side reactions such as degradation of carbohydrate occurs (Kieboom and Van Bekkum, 1984). In Figure 3 the difference between $\mathrm{pH}$ 8.0 and 10.0 is illustrated. For all experiments a smaller rate is observed at $\mathrm{pH}=10.0$.

The temperature was varied in the range of 303-333 $K$. The rate of consumption of methyl $\alpha$-D-glucopyranoside, shown in Figure 4, increases with increasing temperature.

Figure 5 shows the extent of deactivation, expressed as the normalized rate of consumption of methyl $\alpha$-Dglucopyranoside, $R_{w} / R_{w}{ }^{0}$, as a function of the reaction conditions. Surprisingly, the extent of deactivation does not depend on the oxygen partial pressure nor the methyl $\alpha$-D-glucopyranoside or sodium methyl $\alpha$-Dglucuronate concentration as indicated in Figure 5a,b. For a deactivation, which is caused by overoxidation, it was expected that an increase of the oxygen partial pressure would accelerate and an increase of the concentration of a reducing agent like methyl $\alpha-D-$ glucopyranoside would slow down the process of overoxidation. At $\mathrm{pH}=10.0$ the extent of deactivation is larger than that at $\mathrm{pH}=8.0$ as indicated in Figure $5 \mathrm{c}$. In Figure $5 d$ it is shown that the extent of deactivation increases with increasing temperature.

\section{Construction of the Rate Equations for Selective Oxidation and Overoxidation}

Several possible reaction sequences describing the global reaction of methyl $\alpha$-D-glucopyranoside with oxygen and sodium hydroxide toward sodium methyl $\alpha$-D-glucuronate by different adsorption and surface reaction steps were considered in the construction of a kinetic model. Table 2 shows four such sequences. The format is adapted from Temkin (1971) in which the stoichiometric numbers, $\sigma$, indicate the multiplicity of the corresponding reaction step leading to the same global reaction for each reaction path. The intention 

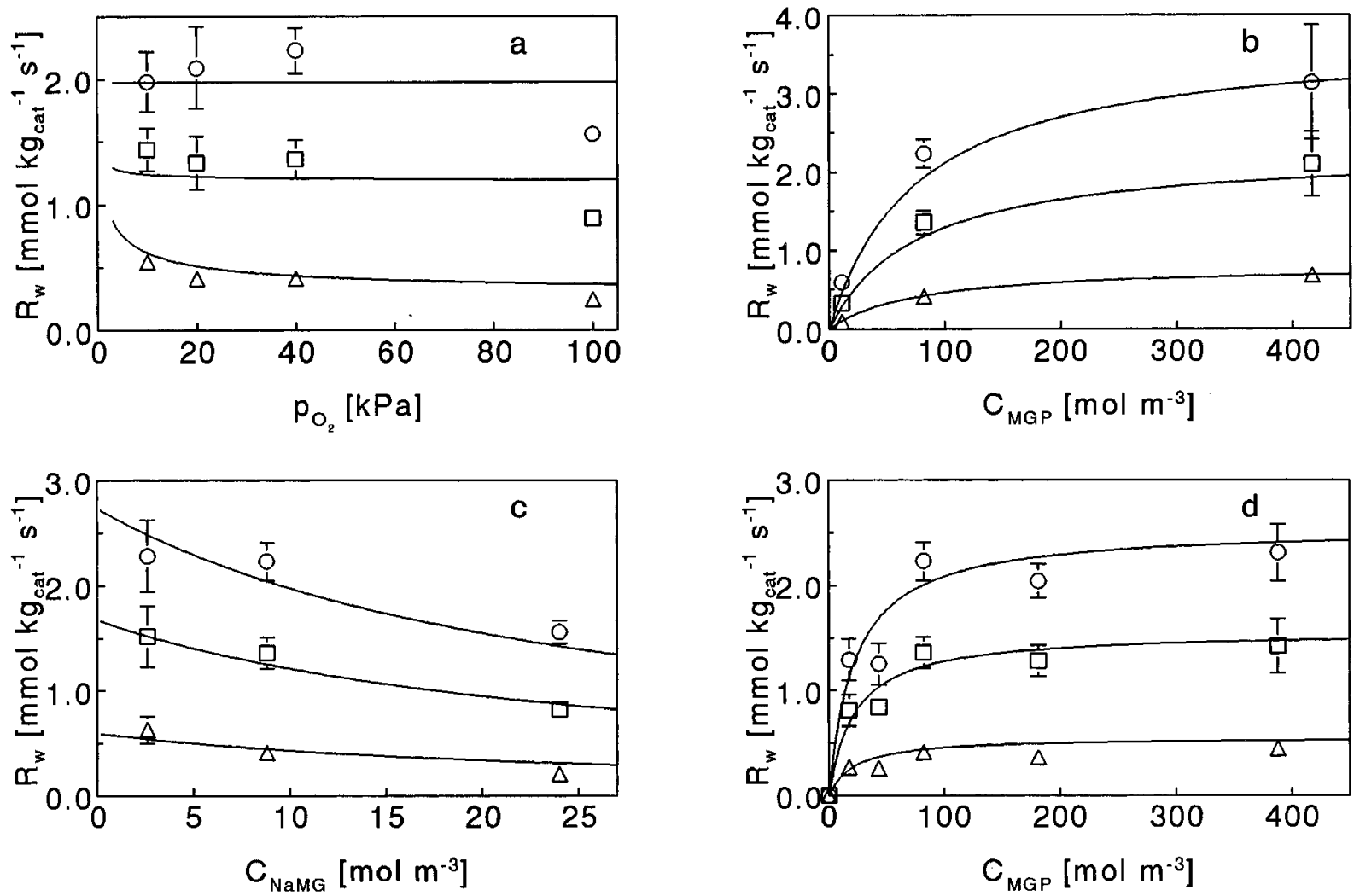

Figure 2. Specific rate of consumption of methyl $\alpha$-D-glucopyranoside, $R_{w}$, at $323 \mathrm{~K}$ and $p H=8.0$ at $(O) t=0 \mathrm{~s},(\square) t=1000 \mathrm{~s}$, and $(\Delta)$ $\mathrm{t}=10000 \mathrm{~s}$ as a function of: (a) the oxygen partial pressure at $\mathrm{C}_{\mathrm{MGP}}=88 \mathrm{~mol} \mathrm{~m}^{-3}$ and $\mathrm{C}_{\mathrm{NaMG}}=9.5 \mathrm{~mol} \mathrm{~m}^{-3}$; (b) the methyl $\alpha-\mathrm{D}-$ glucopyranoside concentration at $\mathrm{p}_{\mathrm{O}_{2}}{ }^{0}=40 \mathrm{kPa}$ and $\mathrm{C}_{\mathrm{NaMG}}=9.5 \mathrm{~mol} \mathrm{~m}^{-3}$; (c) the sodium methyl $\alpha$-D-glucuronate concentration at $\mathrm{P}_{\mathrm{O}_{2}}{ }^{0}$ $=40 \mathrm{kPa}$ and $\mathrm{C}_{\mathrm{MGP}}=82 \mathrm{~mol} \mathrm{~m}{ }^{-3}$; (d) the methyl $\alpha$-D-glucopyranoside concentration at a conversion of $0.10\left(\mathrm{C}_{\mathrm{NaMG}}=0.10 \mathrm{C}_{\mathrm{MGP}}\right)$ and $\mathrm{po}_{2}{ }^{0}$ $=40 \mathrm{kPa}$. Symbols represent experimental data. Lines represent calculated values according to eqs 14 and 15 and parameter values listed in Table 6.

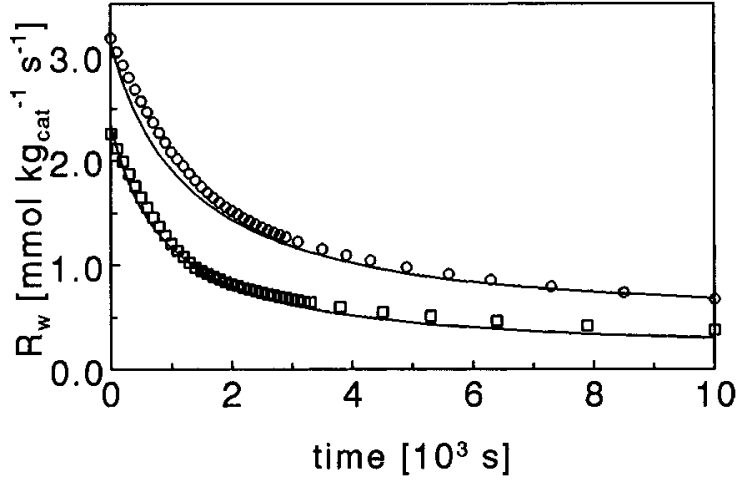

Figure 3. Specific rate of consumption of methyl $\alpha$-D-glucopyranoside for $\mathrm{pH}=(\bigcirc) 8.0$ and $(\square)$ 10.0. Symbols represent experimental data. Lines represent calculated values according to eqs 14 and 15. Conditions were as follows: $\mathrm{T}=323 \mathrm{~K} ; \mathrm{p}_{\mathrm{O}_{2}}{ }^{0}=40 \mathrm{kPa}$; $\mathrm{C}_{\mathrm{MGP}}=420 \mathrm{~mol} \mathrm{~m}^{-3} ; \mathrm{C}_{\mathrm{NaMG}}=10 \mathrm{~mol} \mathrm{~m}^{-3}$.

of the regression analysis is to describe the observed data quantitatively through estimation of parameters with statistical significance. This, however, limits the number of species and reaction and adsorption steps that can be considered.

The chemisorption of molecular oxygen on the platinum surface, step 1 , is generally assumed to be dissociative, either reversibly (Schuurman et al., 1992b) or irreversibly (Nondek et al., 1982; Van den Tillaart et al., 1994). In aqueous phase oxygen adsorption may result in various oxygen species, such as oxygen adatoms and hydroxide species, which feature was used by J elemensky et al. $(1996,1997)$ for the description of multiple steady states and relaxation phenomena for the aqueous phase oxidation of ethanol. In the present

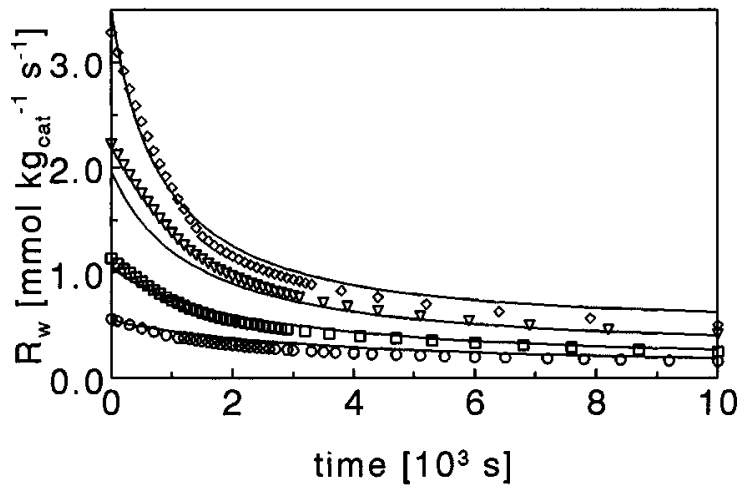

Figure 4. Specific rate of consumption of methyl $\alpha$-D-glucopyranoside for $T=(0) 303 \mathrm{~K},(\square) 313 \mathrm{~K},(\nabla) 323 \mathrm{~K}$ and $(\diamond) 333 \mathrm{~K}$. Symbols represent experimental data. Lines represent calculated values according to eqs 14 and 15 and parameter values listed in Table 6. Conditions were as follows: $\mathrm{pH}=8.0 ; \mathrm{p}_{\mathrm{O}_{2}}{ }^{0}=40 \mathrm{kPa}$; $\mathrm{C}_{\mathrm{MGP}}=86 \mathrm{~mol} \mathrm{~m}^{-3} ; \mathrm{C}_{\mathrm{NaMG}}=10 \mathrm{~mol} \mathrm{~m}^{-3}$.

case only one active adsorbed oxygen species could be considered in order to obtain statistically significant parameter estimates. For the same reason only Langmuir adsorption could be considered, which was also used by Nondek et al. (1982), Schuurman et al. (1992b) and Van den Tillaart et al. (1994), instead of the Temkin/Frumkin type of adsorption (De Bruijn, 1996; J elemensky et al., 1997).

At a high degree of coverage by oxygen, which is concluded from the high catalyst potential in Figure 1, the adsorption of methyl $\alpha$-D-glucopyranoside, step 2, can be described by an associative (N ondek et al., 1982; Schuurman et al., 1992b; J elemensky et al., 1996) rather than a dissociative adsorption. Chemisorption on one 

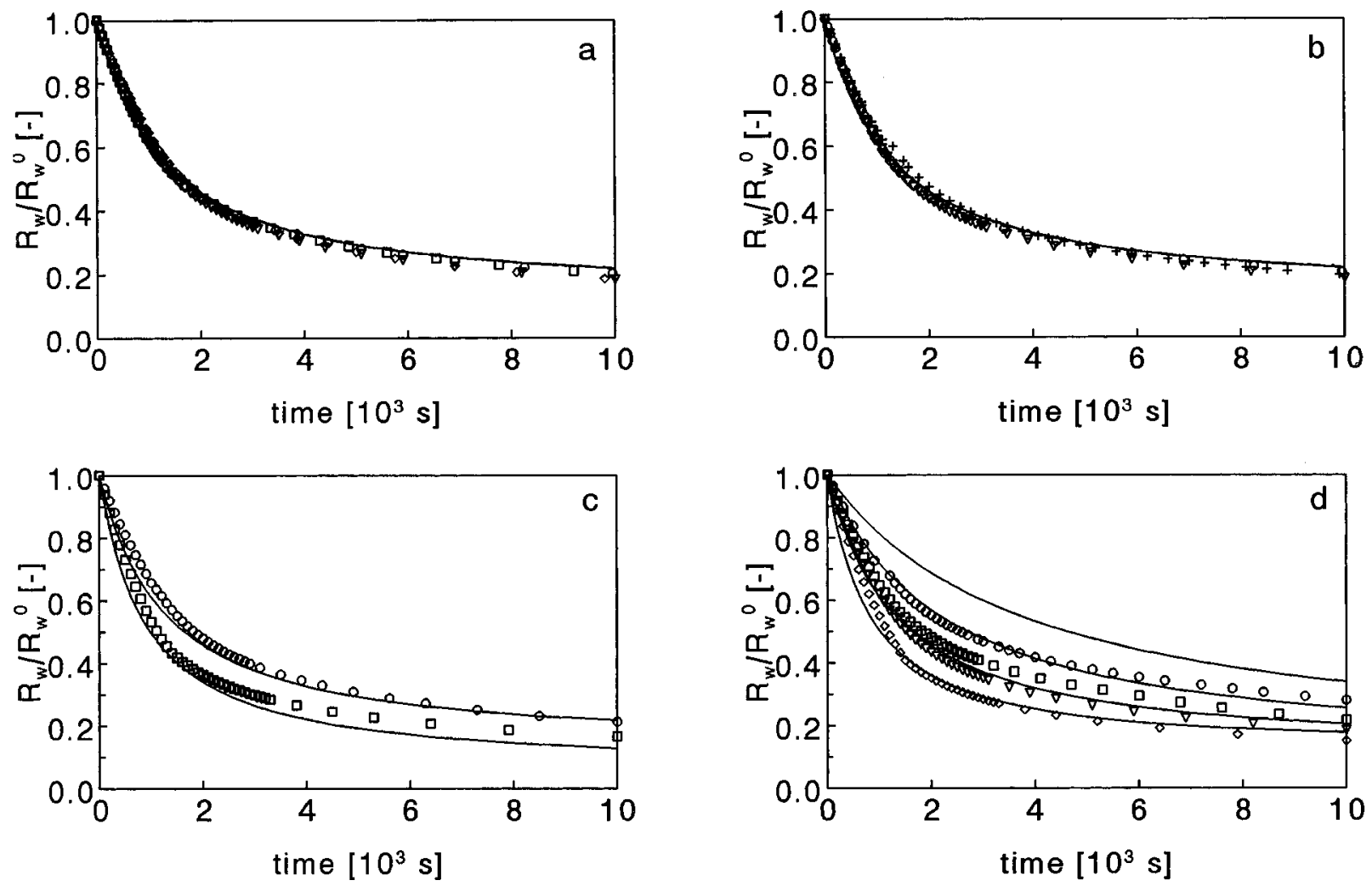

Figure 5. Extent of deactivation or deactivation function, $\varphi_{\text {Oinact, }}$ expressed as the normalized specific rate of consumption of methyl $\alpha$-D-glucopyranoside, $R_{w} / R_{w}{ }^{0}$, for: (a) oxygen partial pressure, $p_{O_{2}}{ }^{0}[\mathrm{kPa}]=(O) 10,(\square) 20,(\nabla) 40$, and $(\diamond) 100$, at $\mathrm{pH}=8.0, \mathrm{C}_{\mathrm{MGP}}=88 \mathrm{~mol}$ $\mathrm{m}^{-3}, \mathrm{C}_{\mathrm{NaMG}}=9.5 \mathrm{~mol} \mathrm{~m}^{-3}$, and $\mathrm{T}=323 \mathrm{~K}$; (b) methyl $\alpha$-D-glucopyranoside concentration at a conversion of $0.10, \mathrm{C}_{\mathrm{NaMG}}$ and $\mathrm{C}_{\mathrm{MGP}}$ (mol $\left.\mathrm{m}^{-3}\right)=(\mathrm{O}) 17.5$ and $2.3,(\nabla) 82$ and $8.8,(+) 388$ and 41 , at $\mathrm{pH}=8.0, \mathrm{p}_{\mathrm{O}_{2}}{ }^{0}=40 \mathrm{kPa}$, and $\mathrm{T}=323 \mathrm{~K} ;(\mathrm{c}) \mathrm{pH}=(\mathrm{O}) 8.0$ and $(\square) 10.0$ at conditions given in Figure 3; (d) temperature, T = (O) $303 \mathrm{~K},(\square) 313 \mathrm{~K},(\nabla) 323 \mathrm{~K}$, and $(\diamond) 333 \mathrm{~K}$ at the conditions given in Figure 4 Symbols represent experimental data. Lines represent calculated values according to eqs 14 and 15.

Table 2. Sequences of Proposed Steps for the Oxidation of Methyl $\alpha$-D-Glucopyranoside, $\mathrm{RCH}_{2} \mathrm{OH}$, toward Sodium Methyl $\alpha$-D-Glucuronate, RCOONa, Assuming Sites for Physisorption, $*_{p}$, and Chemisorption, *, and Subsurface Sites, $*_{\text {sub, }}$ as well as the Transformation of Chemisorbed Oxygen Adatoms, $0 *$, into Subsurface Oxygen, $0 *$ sub.

\begin{tabular}{|c|c|c|c|c|c|}
\hline & & $\sigma_{1}$ & $\sigma_{\mathrm{I}^{\prime}}$ & $\sigma_{\| 1}$ & $\sigma_{111}$ \\
\hline (1a) & $\mathrm{O}_{2}+2 * \rightleftarrows 2 \mathrm{O} *$ & 1 & 0 & 1 & 1 \\
\hline (1b) & $\mathrm{O}_{2}+2 * \rightarrow 2 \mathrm{O}^{*}$ & 0 & 1 & 0 & \\
\hline (2a) & $\mathrm{RCH}_{2} \mathrm{OH}+* \rightleftarrows \mathrm{RCH}_{2} \mathrm{OH}^{*}$ & 1 & 1 & 0 & 0 \\
\hline (2b) & $\mathrm{RCH}_{2} \mathrm{OH}+2^{*} \rightleftarrows \mathrm{RCH}_{2} \mathrm{OH}^{* *}$ & 0 & 0 & 1 & 0 \\
\hline (2c) & $\mathrm{RCH}_{2} \mathrm{OH}+*_{\mathrm{p}} \rightleftarrows \mathrm{RCH}_{2} \mathrm{OH}_{\mathrm{p}}$ & 0 & 0 & 0 & \\
\hline (3a) & $\mathrm{RCH}_{2} \mathrm{OH}^{*}+\mathrm{O}^{*} \rightarrow \mathrm{RCHO}^{*}+*+\mathrm{H}_{2} \mathrm{O}$ & 1 & 1 & 0 & \\
\hline (3b) & $\mathrm{RCH}_{2} \mathrm{OH}^{* *}+\mathrm{O}^{*} \rightarrow \mathrm{RCHO}^{* *}+*+\mathrm{H}_{2} \mathrm{O}$ & 0 & 0 & 1 & \\
\hline (3c) & $\mathrm{RCH}_{2} \mathrm{OH}^{*}{ }_{\mathrm{p}}+\mathrm{O} * \rightarrow \mathrm{RCHO}^{*}+*+\mathrm{H}_{2} \mathrm{O}$ & 0 & 0 & 0 & \\
\hline (4a) & $\mathrm{RCHO}^{*}+\mathrm{O}^{*} \rightarrow \mathrm{RCOOH}^{*}+*$ & 1 & 1 & 0 & \\
\hline (4b) & $\mathrm{RCHO} * *+\mathrm{O}^{*} \rightarrow \mathrm{RCOOH}^{* *}+*$ & 0 & 0 & 1 & \\
\hline (4c) & $\mathrm{RCHO}{ }_{\mathrm{p}}+\mathrm{O} * \rightarrow \mathrm{RCOOH}_{\mathrm{p}}+*$ & 0 & 0 & 0 & \\
\hline (5a) & $\mathrm{RCOOH}^{*}+\mathrm{NaOH} \rightleftarrows \mathrm{RCOONa}+*+\mathrm{H}_{2} \mathrm{O}$ & 1 & 1 & 0 & \\
\hline (5b) & $\mathrm{RCOOH}^{* *}+\mathrm{NaOH} \rightleftarrows \mathrm{RCOONa}+2 *+\mathrm{H}_{2} \mathrm{O}$ & 0 & 0 & 1 & \\
\hline (5c) & $\mathrm{RCOOH}_{\mathrm{p}}+\mathrm{NaOH} \rightleftarrows \mathrm{RCOONa}+*_{\mathrm{p}}+\mathrm{H}_{2} \mathrm{O}$ & 0 & 0 & 0 & \\
\hline (6) & $\mathrm{O} *+*_{\text {sub }} \rightleftarrows \mathrm{O}_{\text {sub }}(+*)^{\mathrm{a}}$ & 0 & 0 & 0 & \\
\hline
\end{tabular}

a Chemisorption site $\left(^{*}\right)$ is not available for chemisorption.

site (reaction path I , I', step 2a) or two sites (reaction path II , step 2b) or physisorption (reaction path III, step 2c) was considered. In the latter case species that are physisorbed on the support are not taken into account and it is assumed that the reacting species, oxygen and methyl $\alpha$-D-glucopyranoside, can adsorb independently. Therefore, two site balances are used, one for physisorption and one for chemisorption. The degree of coverage by methyl $\alpha$-D-glucopyranoside, $\theta_{\mathrm{RCH}_{2} \mathrm{OH}}$, appears in a site balance for physisorption sites and the degree of coverage by oxygen adatoms, $\theta_{\mathrm{O}}$, in the site balance for chemisorption sites, as indicated in Table 3 for reaction path III. The total specific amount of sites for physisorption and chemisorption is taken equal to the specific amount of surface platinum atoms.

The reaction of associatively adsorbed methyl $\alpha-D-$ glucopyranoside and an oxygen adatom, yielding methyl $\alpha$-D-aldehydoglucopyranoside, described in Table 2 by the nonelementary steps $3 a, 3 b$, or $3 c$, is generally considered as the rate-determining step. As shown in Figure 1 methyl $\alpha$-D-al dehydogl ucopyranoside is present only in very small amounts and can therefore be consi dered as a reactive intermediate resulting in a low surface coverage. Hence, the pseudo-first-order rate coefficient of step 3 is much smaller than the pseudofirst-order rate coefficient of step 4, which describes the oxidation of methyl $\alpha$-D-aldehydoglucopyranoside to methyl $\alpha$-D-glucuronic acid. According to Schuurman et al. (1992b) the difference is at least 2 orders of magnitude for the oxidation of methyl $\alpha$-D-glucopyranoside. Therefore, the rate equation that was used for all models is based upon the kinetically significant step, i.e., the reaction of methyl $\alpha$-D-glucopyranoside and an oxygen adatom leading to the formation of methyl $\alpha$-Daldehydoglucopyranoside:

$$
\hat{\mathrm{R}}_{\mathrm{w}}=\mathrm{k}_{3} \mathrm{~L}_{\mathrm{t}} \theta_{\mathrm{O}} \theta_{\mathrm{RCH}_{2} \mathrm{OH}}
$$

Figure 2c clearly shows a decrease of the rate with increasing product concentration. Therefore, the adsorption of oxidation products is incorporated in the model by the adsorption of sodium methyl $\alpha$-D-glucuronate, step $5 a, 5 b$, or $5 c$ in Table 2 . It is assumed that the carboxylic anion is adsorbed as the carboxylic acid and that methyl $\alpha$-D-glucuronic acid adsorbs in the same way as methyl $\alpha$-D-glucopyranoside. 
Ind. Eng. Chem. Res., Vol. 36, No. 9, 19973547

Table 3. Site Balances for Physisorption and Chemisorption and Subsurface Site Balance for Reaction Paths I or I', II, and III from Table 2

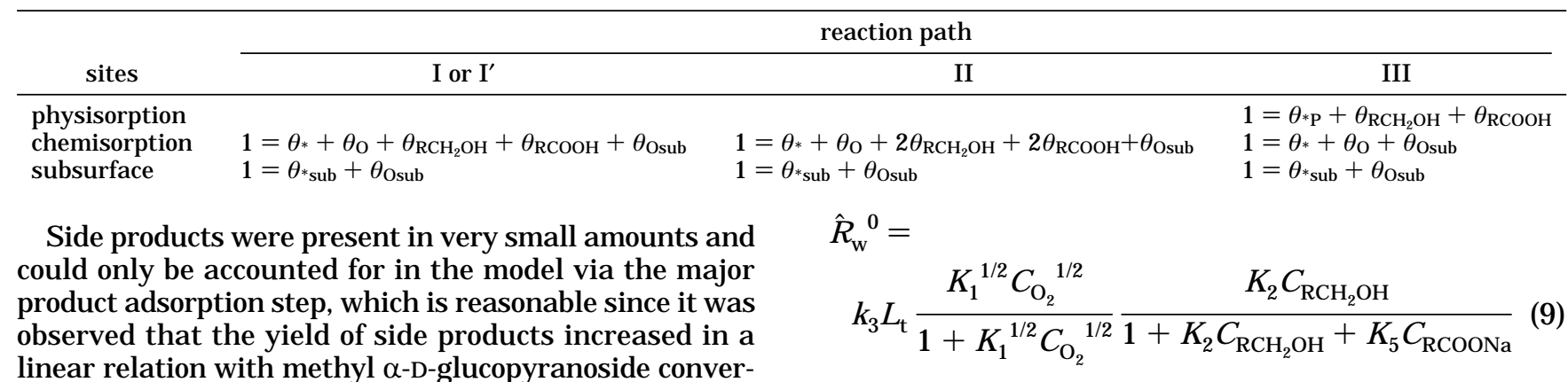
sion. In this way the kinetic analysis is not limited to data obtained at very low conversion.

Deactivation by overoxidation can be described by a step, which describes the transformation of oxygen adatoms into inactive oxygen species. One possible step is step 6 in Table 2, which describes the transformation of oxygen adatoms into inactive so-called subsurface oxygen species, $\mathrm{O}_{\text {sub }}$.

The effect of the $\mathrm{pH}$ could not be accounted for in the kinetic model. The lower rate at $\mathrm{pH}=10.0$ is in contradiction with Schuurman et al. (1992b), who reported a linear increase of the rate at $\mathrm{pH}>8.5$ for the oxidation of methyl $\alpha$-D-glucopyranoside over platinum supported on active carbon. The $\mathrm{pH}$ effect was described by an increase of the concentration of the methyl $\alpha$-D-glucopyranoside anion with increasing $\mathrm{pH}$ and a separate reaction path for the anion. However, the effect of the $\mathrm{pH}$ on the rate of consumption of methyl $\alpha$-D-glucopyranoside may depend on other parameters as well, such as the physical and chemical properties of the catalyst support. This may for example affect the physisorption or chemisorption of oxygen, methyl $\alpha$-D-glucopyranoside, and (side) products. Also, the concentration of the intermediate aldehyde and side products is $\mathrm{pH}$ dependent. From Figure $5 \mathrm{c}$ it is clear that the extent of deactivation also depends on the $\mathrm{pH}$. The dependence of the overoxidation on the $\mathrm{pH}$ may also be caused by several of the phenomena mentioned. Therefore, the complexity of the pH effect cannot be attributed to one clear effect and could not be accounted for in a kinetic model. Consequently, the regression analyses of the data at $\mathrm{pH}=8.0$ and 10.0 were performed separately and two sets of kinetic parameters were obtained, one describing the data at $\mathrm{pH}=8.0$ and the other describing the data at $\mathrm{pH}=$ 10.0 .

The regression analysis was divided in several parts. First, the regression analysis of the data is performed for the initial rates, i.e., without taking into account the effect of overoxidation. Next, the regression analysis is extended to all data in the time interval between 0 and $10000 \mathrm{~s}$, estimating all parameters simultaneously. Finally, the temperature effect is taken into account by considering the Arrhenius dependency of the rate coefficients.

Selective Oxidation in the Absence of Deactivation. In first instance discrimination between the models based on the reaction paths proposed in Table 2 was based on regression analysis of the initial rates by omission of step 6, assuming no presence of subsurface oxygen, $\theta_{\text {Osub }}=0$. Rate equations were derived from eq 8 for each reaction path considered. For reaction path $\mathrm{III}$, for example, the following equation can be derived:

Regression of initial rates with the obtained equations did not result in statistically significant parameter estimates for any of the reaction paths considered. Therefore, the number of parameters was reduced by the approximation that the relative number of vacant sites is much smaller than the relative number of sites covered by oxygen atoms, i.e., $\theta_{*}<<\theta_{\mathrm{O}}$. This is allowed since it was shown that during oxidation the degree of coverage by oxygen is high. For reaction path III, for example, eq 9 is approximated by:

$$
\hat{\mathrm{R}}_{\mathrm{w}}{ }^{0}=\frac{\mathrm{K}_{3} \mathrm{~L}_{\mathrm{t}} \mathrm{K}_{2} \mathrm{C}_{\mathrm{RCH}_{2} \mathrm{OH}}}{1+\mathrm{K}_{2} \mathrm{C}_{\mathrm{RCH}_{2} \mathrm{OH}}+\mathrm{K}_{5} \mathrm{C}_{\mathrm{RCOONa}}}
$$

since $\left(\mathrm{K}_{1}{ }^{1 / 2} \mathrm{C}_{\mathrm{O}_{2}}{ }^{1 / 2}\right) /\left(1+\mathrm{K}_{1}{ }^{1 / 2} \mathrm{C}_{2}{ }^{1 / 2}\right) \approx 1$.

The regression results obtained for reaction paths $\mathrm{I}$, $I^{\prime}, I I$, and III areillustrated in Figure 6 . It is concluded from the higher F-ratio or global significance for reaction path I compared to reaction path I' and the results shown in Figure 6 that reversible oxygen adsorption (step 1a) describes much better the experimental data than irreversible adsorption (step 1b). Also for other reaction paths the significance of the gl obal regression was greatly improved if a reversible oxygen adsorption step was incorporated in the model instead of irreversible oxygen adsorption, which is in agreement with Schuurman et al. (1992b).

Adsorption of methyl $\alpha$-D-glucopyranoside and methyl $\alpha$-D-glucuronic acid on two sites (reaction path II) instead of one site (reaction path I) leads to a higher global significance. However, the effect is rather small, since a large simi larity between reaction paths I and II concerning the description of the experimental data is observed in Figure 6.

The highest global significance was calculated for reaction path $\mathrm{III}$, for which the parameter estimates at $\mathrm{pH}=8.0$ are listed in Table 4 . Note that due to the necessary reduction of the number of parameters the kinetic rate equation for reaction path III, eq 10 , does not depend on the oxygen concentration at all, which is clearly observed in Figure 6 . The dependence of reaction path III on the oxygen concentration is expressed by the term $\mathrm{K}_{1}{ }^{1 / 2} \mathrm{C}_{\mathrm{O}_{2}}{ }^{1 / 2} /\left(1+\mathrm{K}_{1}{ }^{1 / 2} \mathrm{C}_{\mathrm{O}_{2}}{ }^{1 / 2}\right)$, shown in eq 9 . This term is not much different from one at high oxygen concentration. At low oxygen concentration, however, this term cannot be neglected and eq 9 rather than eq 10 should be applied.

The Langmuir adsorption equilibrium constants for methyl $\alpha$-D-glucopyranoside or methyl $\alpha$-D-glucuronic acid are at least $10^{2}$ smaller than the adsorption equilibrium constant for oxygen, $\mathrm{K}_{1}$, which could not be estimated, but amounts to approximately $10 \mathrm{~m}^{3} \mathrm{~mol}^{-1}$ at $323 \mathrm{~K}$ (Schuurman et al., 1992c). From this it is calculated that the standard Gibbs energy of adsorption 

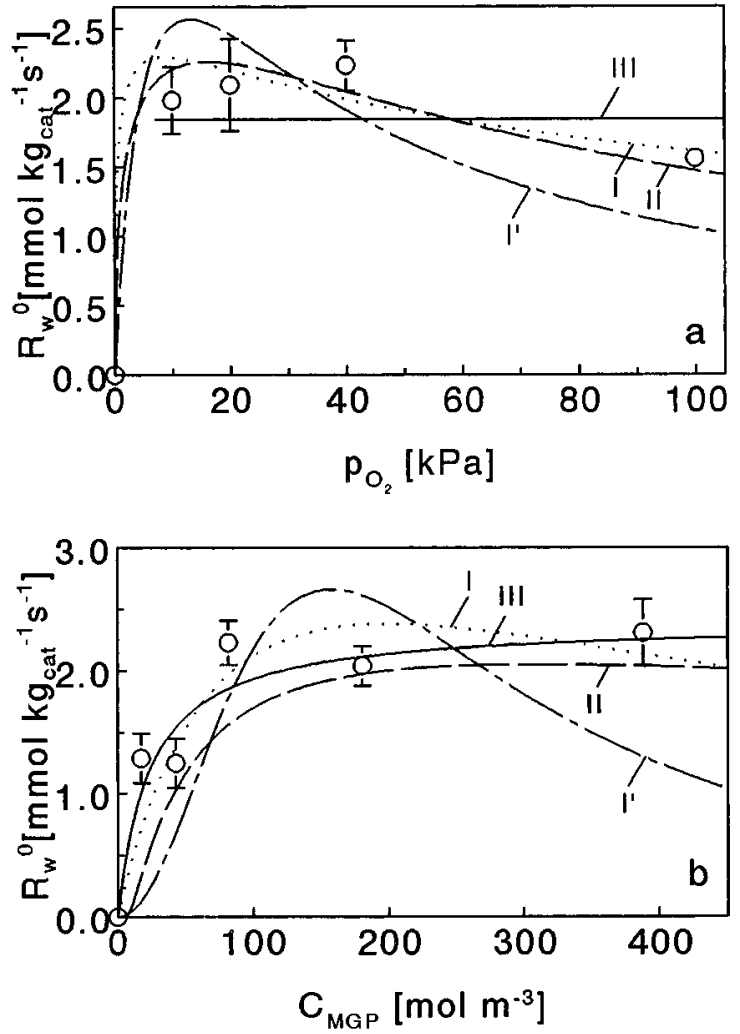

Figure 6. Specific initial rate of consumption of methyl $\alpha$-Dglucopyranoside, $\mathrm{R}_{\mathrm{w}}{ }^{0}$, at $323 \mathrm{~K}$ and $\mathrm{pH}=8.0$ as a function of (a) the oxygen partial pressure at $\mathrm{C}_{\mathrm{MGP}}=88 \mathrm{~mol} \mathrm{~m}^{-3}$ and $\mathrm{C}_{\mathrm{NaMG}}=$ $9.5 \mathrm{~mol} \mathrm{~m}^{-3}$ and (b) the methyl $\alpha$-D-glucopyranoside concentration at a conversion of $0.10\left(\mathrm{C}_{\mathrm{NaMG}}=0.10 \mathrm{C}_{\mathrm{MGP}}\right)$ and $\mathrm{p}_{\mathrm{O}_{2}}{ }^{0}=40 \mathrm{kPa}$ : (O) experimental data; lines calculated according to the rate equations derived for reaction paths $I, I^{\prime}, I I$, and III .

Table 4. Parameter Estimates with $95 \%$ Confidence Limits for Reaction Path III by Regression of $\mathbf{R}_{\mathrm{w}}{ }^{0}$ Data, Equation 10, and $R_{w}(t)$ Data, Equations $14^{\mathrm{a}}$ and 15, at 323 $\mathrm{K}$ and $\mathrm{pH}=\mathbf{8 . 0}$

\begin{tabular}{lcc}
\hline reaction path III & $\mathrm{R}_{\mathrm{w}}{ }^{0}(\mathrm{t}=0 \mathrm{~s})$ & $\mathrm{R}_{\mathrm{w}}(0 \leq \mathrm{t} \leq 10000 \mathrm{~s})$ \\
\hline $\mathrm{K}_{2}\left(10^{-2} \mathrm{~m}^{3} \mathrm{~mol}^{-1}\right)$ & $3.1 \pm 2.6$ & $3.11 \pm 0.36$ \\
$\mathrm{~K}_{3}\left(10^{-2} \mathrm{~s}^{-1}\right)$ & $4.6 \pm 1.1$ & $5.08 \pm 0.20$ \\
$\mathrm{~K}_{5}\left(10^{-1} \mathrm{~m}^{3} \mathrm{~mol}^{-1}\right)$ & $1.1 \pm 1.4$ & $1.44 \pm 0.23$ \\
$\mathrm{~K}_{6}\left(10^{-4} \mathrm{~s}^{-1}\right)$ & & $6.82 \pm 0.59$ \\
$\mathrm{~K}_{-6} \mathrm{~K}_{1}^{-1 / 2}\left(10^{-5} \mathrm{~s}^{-1}\right.$ & & $9.0 \pm 2.2$ \\
$\left.\quad \mathrm{~m}^{-3 / 2} \mathrm{~mol}^{1 / 2}\right)$ & 231 & 6275 \\
$\mathrm{~F}_{- \text {ratio }}$ & & \\
${ }^{\mathrm{a}} \mathrm{L}_{\mathrm{t}}=0.073 \mathrm{~mol} \mathrm{~kg}_{\text {cat }}{ }^{-1}$. &
\end{tabular}

for methyl $\alpha$-D-glucopyranoside and methyl $\alpha$-D-glucuronic acid amounts to -9 and $-6 \mathrm{~kJ} \mathrm{~mol}^{-1}$, respectively. These relatively low values, which were also found for reaction paths I and II, point to physisorption rather than chemi sorption of methyl $\alpha$-D-glucopyranoside and methyl $\alpha$-D-glucuronic acid. The difference between oxygen chemisorption and carbohydrate physisorption is expressed in reaction path III and can be understood from the large differences in geometrical size and adsorption energy between oxygen and methyl $\alpha$-Dglucopyranoside or methyl $\alpha$-D-glucuronic acid.

Other models were proposed in which physisorption of methyl $\alpha$-D-glucopyranoside is followed by a reversible or irreversible chemisorption, but these models were rejected because of the lower global significance and poor description of the experimental data.

The small number of experimental data used in the regression analysis of the initial rates results in a low significance for the global regression and the individual parameters, which was observed for all reaction paths.
As a consequence discrimination between reaction paths $\mathrm{I}, \mathrm{II}$, and III is rather difficult. Also, no $\mathrm{pH}$ dependence can be concluded, because equal parameter estimates for $\mathrm{pH}=8.0$ and 10.0 are obtained within the $95 \%$ confidence limits. The extensi on of the kinetic regression to all data will lead to an improvement of the significance of the parameter estimates and facilitate the discrimination.

Selective Oxidation in the Presence of Deactivation. The extension of data regression to $t>0 \mathrm{~s}$, i.e., in the presence of deactivation due to overoxidation, necessitates the introduction of a side relaxation process. Several steps that can describe the transformation of oxygen adatoms into less or inactive oxygen were tried, which will be discussed in the next section. Step 6 in Table 2, representing a reversible surface reaction of an oxygen adatom, O*, with a subsurface site, $*_{\text {sub, }}$ creating a so-called subsurface oxygen atom (L auterbach et al., 1994), O* sub, resulted in the highest global significance and the most adequate description of the experimental data. For step 6 it is assumed that the formation of subsurface oxygen leads to an inactive chemisorption site. Therefore, subsurface oxygen appears in the subsurface site balance and the site balance for chemisorption, as shown in Table 3. The rate of formation of subsurface oxygen, step 6 is given by:

$$
\mathrm{r}_{\text {Osub }}=\mathrm{k}_{6} \theta_{\mathrm{O}} \theta_{* \text { sub }}-\mathrm{k}_{-6} \theta_{\text {Osub }} \theta_{*}
$$

Rate equations for the proposed reaction paths were derived from eqs 8 and 11 and the site balances shown in Table 3. Because the time scale of the side relaxation process, step 6 , is much larger than the intrinsic relaxation time, a steady state approximation of the reactive surface intermediates was applied and steps 1,2 , and 5 are considered to be in quasi-equilibrium. For reaction path III, for example, the following equations are obtained:

$$
\begin{aligned}
& \hat{\mathrm{R}}_{\mathrm{w}}= \\
& \mathrm{K}_{3} \mathrm{~L}_{\mathrm{t}} \frac{\mathrm{K}_{1}{ }^{1 / 2} \mathrm{C}_{\mathrm{O}_{2}}{ }^{1 / 2}}{1+\mathrm{K}_{1}{ }^{1 / 2} \mathrm{C}_{\mathrm{O}_{2}}{ }^{1 / 2}} \frac{\mathrm{K}_{2} \mathrm{C}_{\mathrm{RCH}_{2} \mathrm{OH}}}{1+\mathrm{K}_{2} \mathrm{C}_{\mathrm{RCH}_{2} \mathrm{OH}}+\mathrm{K}_{5} \mathrm{C}_{\mathrm{RCOONa}}} \times \\
& \frac{\mathrm{d} \theta_{\text {Osub }}}{\mathrm{dt}}=\mathrm{k}_{6} \frac{\mathrm{K}_{1}{ }^{1 / 2} \mathrm{C}_{\mathrm{O}_{2}}{ }^{1 / 2}}{1+\mathrm{K}_{1}^{1 / 2} \mathrm{C}_{\mathrm{O}_{2}}{ }^{1 / 2}}\left(1-\theta_{\text {Osub }}\right)^{2}- \\
& \mathrm{k}_{-6} \frac{1}{1+\mathrm{K}_{1}^{1 / 2} \mathrm{C}_{\mathrm{O}_{2}}{ }^{1 / 2}} \theta_{\text {Osub }}\left(1-\theta_{\text {Osub }}\right)
\end{aligned}
$$

Regression with the obtained equations did not result in statistically significant parameter estimates for any of the reaction paths considered. Therefore, parameter reduction was performed by the approximation that $\theta *$ $\ll \theta_{\mathrm{O}}$, which was also used in the previous section. For reaction path III, for example, eqs 12 and 13 are reduced to

$$
\begin{gathered}
\hat{\mathrm{R}}_{\mathrm{w}}=\frac{\mathrm{k}_{3} \mathrm{~K}_{2} \mathrm{~L}_{\mathrm{t}} \mathrm{C}_{\mathrm{RCH}_{2} \mathrm{OH}}}{1+\mathrm{K}_{2} \mathrm{C}_{\mathrm{RCH}_{2} \mathrm{OH}}+\mathrm{K}_{5} \mathrm{C}_{\mathrm{RCOONa}}}\left(1-\theta_{\mathrm{Osub}}\right) \\
\mathrm{d} \theta_{\text {Osub }} \mathrm{dt}=\mathrm{k}_{6}\left(1-\theta_{\mathrm{Osub}}\right)^{2}- \\
\mathrm{k}_{-6} \mathrm{~K}_{1}{ }^{-1 / 2} \mathrm{C}_{\mathrm{O}_{2}}{ }^{-1 / 2} \theta_{\text {Osub }}\left(1-\theta_{\text {Osub }}\right)
\end{gathered}
$$

It follows from eq 3 that the deactivation function, 
$\varphi$ Oinact, can be written as

$$
\varphi_{\text {Oinact }}=\frac{\hat{\mathrm{R}}_{\mathrm{w}}}{\hat{\mathrm{R}}_{\mathrm{w}}{ }^{0}}=\left(1-\theta_{\text {Osub }}\right)^{\mathrm{n}_{*}}=\left(\frac{\mathrm{L}_{\mathrm{t}}-\mathrm{L}_{\text {Osub }}}{\mathrm{L}_{\mathrm{t}}}\right)^{\mathrm{n} *}
$$

in which $n *$ corresponds to the number of active sites involved in the rate-determining step of the reaction, step 3 in Table 2 (Froment and Bischoff, 1990). For reaction path III $n *$ equals 1 .

Reaction path III offers the most adequate description of the experimental data. The results of the regression with eqs 14 and 15 are shown in Table 4 for $\mathrm{pH}=8.0$. All parameter estimates are statistically significant. The highest binary correlation coefficient between the individual parameters amounts only to 0.71 .

The highest global significance or F-ratio is calculated for reaction path $\mathrm{III}$, which is even more pronounced for $\mathrm{pH}=10.0$ than for $\mathrm{pH}=8.0$. According to the F-test (F roment and Bischoff, 1990) the $F$-ratio is significantly higher, because 480 data at $\mathrm{pH}=8.0$ and 360 data at $\mathrm{pH}=10$ were used for the kinetic regression with only five parameters. However, the $40\left(t, R_{w}\right)$ data of each experiment are correlated and a straightforward application of the F-test can be questioned. All parameter estimates are statistical ly significant and the parameter estimates obtained for the regression of initial rates did not change within the $95 \%$ confidence limits upon the addition of step 6 to reaction paths I, II, and III .

Furthermore, reaction path III provides a better description of the experimental data than reaction paths I and II, concerning the independence of the deactivation function, $\varphi$ oinact, or the extent of overoxidation on the oxygen partial pressure and the methyl $\alpha$-D-glucopyranoside or sodium methyl $\alpha$-D-glucuronate concentration, as shown in parts $a$ and $b$ of Figure 5 . According to reaction paths I and II a lower oxygen partial pressure and a higher methyl $\alpha$-D-glucopyranoside and sodium methyl $\alpha$-D-gl ucuronate concentration will lead to an increase of $\theta_{\mathrm{RCH}_{2} \mathrm{OH}}$ and $\theta_{\mathrm{RCOOH}}$ relative to $\theta_{0}$. Consequently, the rate of transformation of oxygen adatoms into subsurface oxygen, i.e., the extent of deactivation, is decreased, which is in disagreement with the experimental results shown in Figure $5 a, b$. The independence of the rate of transformation of oxygen adatoms into subsurface oxygen on the methyl $\alpha$-Dglucopyranoside and sodium methyl $\alpha$-D-glucuronate concentration is also evident from eq 15 . The dependence of the rate of formation of subsurface oxygen on the oxygen partial pressure is limited to $\mathrm{C}_{2}{ }^{-1 / 2}$, which only appears in the reverse-transformation of subsurface oxygen into surface oxygen. Therefore, the experimental data are more adequately described by reaction path III.

The effect of the $\mathrm{pH}$ on the reaction rate coefficients and adsorption constants is small with the exception of the adsorption constant for methyl $\alpha$-glucuronic acid, $\mathrm{K}_{5}$, which is much higher at higher $\mathrm{pH}$. This indicates that the reversible adsorption must be attributed to side product adsorption rather than to adsorption of the main reaction product, because at $\mathrm{pH}=10.0$ the amount of side products is higher at equal conversion. It could not be determined which product is responsible for reversible site coverage. Adsorption of mono- and dicarboxylic anions is less likely since it is expected that these species adsorb more strongly on the platinum surface at lower instead of higher pH (Abbadi and Van Bekkum, 1995).

For none of the considered reaction paths does the addition of a side relaxation step, describing the revers-
Table 5. Proposed Steps for the Transformation of Oxygen Adatoms into Inactive Oxygen

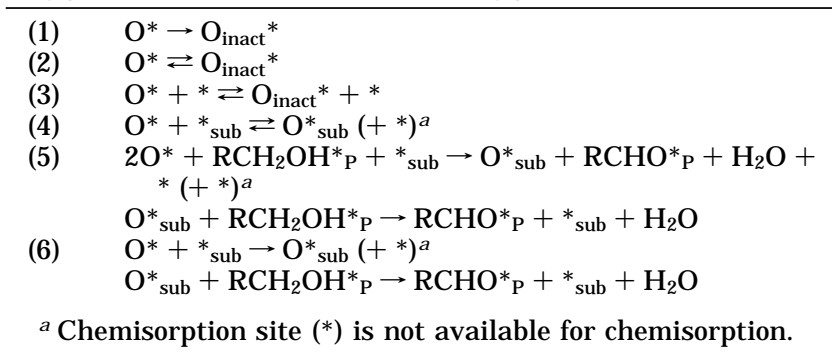

ible formation of inactive subsurface oxygen, lead to kinetic parameter estimates different from those obtained from the regression analysis of the initial rates only. Indeed, the parameter estimates in Table 4 did not change within the $95 \%$ confidence limits upon extension of the regression to data obtained at $t>0 \mathrm{~s}$. This supports the fact that a distinction can be made between the intrinsic relaxation process on a time scale of seconds, in which steady-state surface coverages are expected, and the extrinsic or side relaxation process, which causes deactivation. This distinction is confirmed by the high ratio of the rate coefficient of the ratedetermining step 3 and the rate coefficient of step 6 , $\mathrm{k}_{3} / \mathrm{k}_{6}$, which amounts to 75 for reaction path III.

No relative improvement for data regression in the presence of deactivation is observed for models that already describe the initial data less adequately. For example, addition of step 6 to reaction path I', which assumes irreversible oxygen adsorption, does not improve the global significance to such an extent that the adequacy of the description of the experimental data is better than that for reversible oxygen adsorption (reaction path I). This is another indication that the addition of a step, which describes the side relaxation process due to overoxidation, does not influence the intrinsic kinetic parameter estimates of the main reaction.

Overoxidation of the Catalyst. The deactivation by overoxidation can be described by a step in which inactive oxygen is formed. Possible steps that were tried in order to describe the transformation of oxygen into inactive oxygen are listed in Table 5.

Less adequate descriptions were obtained when the transformation of oxygen into inactive oxygen was considered as an irreversible step. Step 1 in Table 5 represents the most simple irreversible transformation, resulting in an exponential decay of the rate with time and, hence, a linear relation between $\ln \left(R_{w} / R_{w} 0\right)$ and $t$, which is in disagreement with the experimental data. Moreover, overoxidation is clearly reversible as shown in Figure 1.

When no distinction was made between sites for active oxygen adatoms and inactive oxygen, steps 2 and 3 in Table 5, the data are described less adequately than for step 4. A lower gl obal significance was also obtained when deactivation by overoxidation is chemically coupled to the rate of reaction between methyl $\alpha$-D-glucopyranoside and oxygen as indicated in Table 5 by step 5 . Dirkx and Van der Baan (1981a) reported such a correlation for the oxidation of glucose. Finally, the regression results did not improve when the removal of subsurface oxygen was described by a reaction between adsorbed methyl $\alpha$-D-glucopyranoside and subsurface oxygen (step 5 or 6 , Table 5).

From the foregoing it can be concluded that step 4 in Table 5 most adequately describes the deactivation by overoxidation via the transformation of oxygen adatoms 
Table 6. Parameter Estimates Obtained by Regression of all Experimental Data at $\mathbf{p H}=\mathbf{8 . 0}$ in the Time Interval 0 $\leq t \leq 10000$ s for Reaction Path III, Equations 14 and 15, and the Experimental Range Listed in Table 1

\begin{tabular}{|c|c|}
\hline 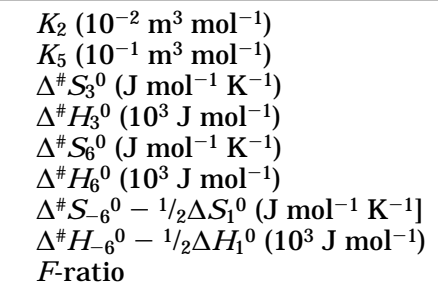 & $\begin{array}{l}3.05 \pm 0.32 \\
1.44 \pm 0.21 \\
-111 \pm 12 \\
51.3 \pm 4.0 \\
-174 \pm 36 \\
44 \pm 12 \\
-192 \pm 37 \\
50 \pm 12 \\
6240\end{array}$ \\
\hline${ }^{a} L_{t}=0.073 \mathrm{~mol} \mathrm{~kg}_{\mathrm{cat}^{-1}}{ }^{-1}$ & \\
\hline
\end{tabular}

into inactive subsurface oxygen. Whereas for reaction path III in Table 2 the rate of consumption of methyl $\alpha$-D-gl ucopyranoside, the rate-determining step, has a first-order dependence on the fraction of subsurface oxygen (eq 14), the rate of formation of subsurface oxygen shows a second-order dependence in eq 15. Apparently the rate of formation of subsurface oxygen is better described by a second-order dependence than by a first-order dependence, which results from steps 1 and 2, Table 5, or a third-order dependence obtained for step 5, Table 5 .

\section{Assessment of Arrhenius Parameters}

Simultaneous estimation of the standard activation entropies, $\Delta^{\# S^{0}}$, and enthal pies, $\Delta^{\#} \mathrm{H}^{0}$, standard reaction entropies, $\Delta S^{0}$, and enthal pies, $\Delta H^{0}$, via eq 6 and 7 was performed, using all data at $\mathrm{pH}=8.0$ in the temperature range of $303-333 \mathrm{~K}$. Incorporation of a temperature dependence for the adsorption constants did not result in realistic and statistically significant parameter estimates. Therefore, the temperature dependence of the adsorption constants was not accounted for.

Model discrimination between reaction paths I, II, and III could not be performed on the basis of the temperature dependence of the parameter estimates. Therefore, only the parameter estimates for reaction path III, which has the highest global significance, are listed in Table 6 . Note that for parameter $\mathrm{k}_{-6} / \mathrm{K}_{1}-1 / 2$ a combination of a standard activation and adsorption enthalpy or entropy, $\Delta^{\# S} S_{-6}{ }^{0}-1 / 2 \Delta S_{1}{ }^{0}$ and $\Delta^{\#} H_{-6}{ }^{0}-1 / 2 \Delta H_{1}{ }^{0}$, is obtained. The adequate description of the temperature dependence of the experimental data by eqs 14 and 15 is illustrated in Figure 4. In Figure $5 d$ it is observed that at 323 and $333 \mathrm{~K}$ the extent of deactivation is more adequately described than at 303 and $313 \mathrm{~K}$.

The capability of reaction path III to describe the experimental data is shown in the parity diagram in Figure 7 for the regression of all experimental data at $\mathrm{pH}=8.0$ with eqs 14 and 15 and the parameter values listed in Table 6. For the experiments at $\mathrm{pH}=10$ equal results were obtained with parameter estimates that were almost identical to those at $\mathrm{pH}=8.0$, with the exception of $\mathrm{K}_{5}$, which is 50 times larger in order to account for more (side) product adsorption. The adequate description of the data by reaction path III is also illustrated in Figures $2-5$, in which a good agreement is observed between the calculated rates, represented by the full lines, and the experimental data, represented by the symbols.

The resulting parameter estimates of the adsorption constants of methyl $\alpha$-D-glucopyranoside and methyl $\alpha$-D-glucuronic acid, $K_{2}$ and $K_{5}$, in Table 6 are equal within the $95 \%$ confidence limits to the parameter

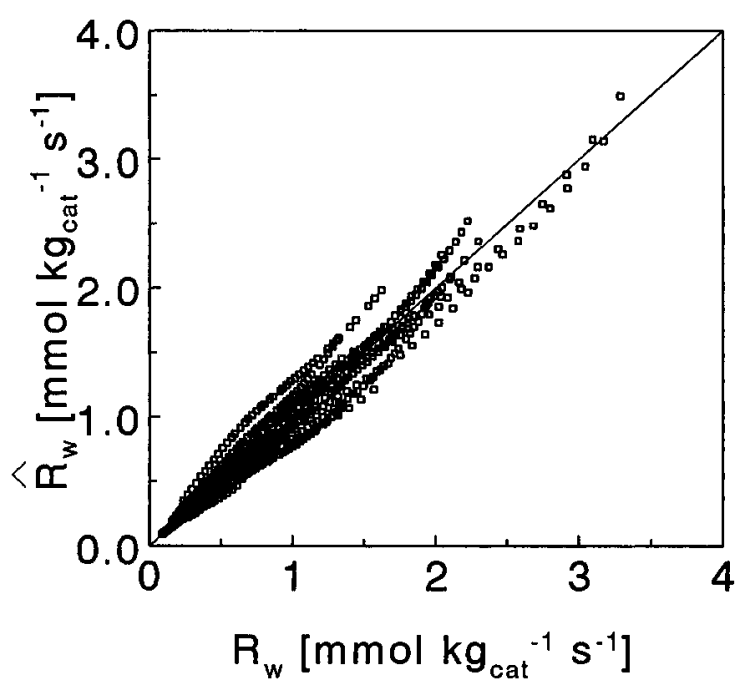

Figure 7. Parity diagram for all experiments at $\mathrm{pH}=8.0$, indicating the calculated specific rate of consumption of methyl $\alpha$-D-glucopyranoside, according to eqs 14 and 15 and parameter values in Table 6 , versus the experimental rate for the conditions listed in Table 1.

estimates that were obtained in Table 4. Their temperature independence confirms the idea that methyl $\alpha$-D-glucopyranoside and methyl $\alpha$-D-glucuronic acid adsorption can be considered as physisorption rather than chemisorption. The higher value of $K_{5}$ versus $K_{2}$ is in agreement with the idea that even at small (side) product concentrations site coverage occurs, which results in a decrease of the rate.

The standard activation entropy of the rate-determining step (3c) in Table 2 amounts to $-111 \mathrm{~J} \mathrm{~mol}^{-1} \mathrm{~K}^{-1}$ and the standard activation enthalpy to $51.3 \mathrm{~kJ}$ $\mathrm{mol}^{-1}$. These values are in good agreement with Schuurman et al. (1992c), who reported respectively $-116 \mathrm{~J} \mathrm{~mol}^{-1} \mathrm{~K}^{-1}$ and $50.5 \mathrm{~kJ} \mathrm{~mol}^{-1}$. The negative standard activation entropy can be explained by a strong steric requirement of the rate-determining step or by the fact that the rate-determining step is not elementary. According to reaction path III the ratedetermining step consists of a reaction between a physisorbed large molecule, methyl $\alpha$-D-glucopyranoside, and a chemisorbed small oxygen adatom. Hence, the steric requirement can be explained from the difference in geometric size of both reactants or from the orientation of the methyl $\alpha$-D-glucopyranoside molecule to the active site. The second explanation that the rate-determining step $3 c$ in Table 2 is not el ementary also holds. Step (3c) can be considered as a combination of elementary steps in which the ratedetermining elementary step may be preceded by an equilibrium, such as the reversible chemisorption of methyl $\alpha$-D-glucopyranoside from its physisorption state. In that case the apparent reaction rate coefficient is the product of the true reaction rate coefficient and an equilibrium constant and the apparent standard activation entropy is written as:

$$
\Delta^{\#} \mathrm{~S}_{\mathrm{app}}{ }^{0}=\Delta^{\# \mathrm{~S}^{0}}+\Delta \mathrm{S}^{0}
$$

Hence, when the preceding adsorption equilibrium has a strongly negative standard entropy, the apparent standard activation entropy may become negative.

The relative low value of the standard activation enthal py may al so be explained by the assumption that step $3 c$ in Table 2 is not an elementary step and is 
preceded by an equilibrium, resulting in

$$
\Delta^{\#} \mathrm{H}_{\mathrm{app}}{ }^{0}=\Delta^{*} \mathrm{H}^{0}+\Delta \mathrm{H}^{0}
$$

Consequently, the apparent standard activation enthalpy is lowered with respect to the real activation enthalpy of the rate-determining step in the case that the preceding equilibrium is exothermic.

The standard activation entropy for the transformation of oxygen adatoms into subsurface oxygen is strongly negative, and the standard activation enthalpy is positive. The calculated standard activation enthal py for the transformation of oxygen into subsurface oxygen is in good agreement with the results of Lauterbach et al. (1994), who reported an activation energy of $63 \pm$ $21 \mathrm{~kJ} \mathrm{~mol}^{-1}$ on a $\mathrm{Pt}(100)$ single crystal at $455 \mathrm{~K}$ under ultrahigh vacuum conditions.

The standard activation entropy and enthal py for the reverse transformation can be calculated from the parameter estimates $\Delta^{\#} S_{-6}{ }^{0}-1 / 2 \Delta S_{1}{ }^{0}$ and $\Delta^{\#} H_{-6}{ }^{0}-$ $1 / 2 \Delta \mathrm{H}_{1}{ }^{0}$. Schuurman et al. (1992c) reported for the selective oxidation of methyl $\alpha$-D-glucopyranoside that $\Delta \mathrm{S}_{1}{ }^{0}=-107 \pm 40 \mathrm{~J} \mathrm{~mol}^{-1} \mathrm{~K}^{-1}$ and $\Delta \mathrm{H}_{1}{ }^{0}=-60 \pm 11$ $\mathrm{kJ} \mathrm{mol}{ }^{-1}$, which results in $\Delta^{\#} S_{-6}{ }^{0}=-139 \pm 58 \mathrm{~J} \mathrm{~mol}^{-1}$ $\mathrm{K}^{-1}$ and $\Delta^{\#} \mathrm{H}_{-6}{ }^{0}=80 \pm 24 \mathrm{~kJ} \mathrm{~mol}^{-1}$. From this the standard reaction entropy and enthalpy of step 6 is calculated: $\Delta \mathrm{S}_{6}{ }^{0}=-35 \pm 16 \mathrm{~J} \mathrm{~mol}^{-1} \mathrm{~K}^{-1}$ and $\Delta \mathrm{H}_{6}{ }^{0}=$ $-36 \pm 15 \mathrm{~kJ} \mathrm{~mol}^{-1}$. The negative value of the standard reaction entropy of step 6 can be understood from the expected loss of entropy which occurs when oxygen is transferred into subsurface oxygen and is more strongly bound to platinum. The standard reaction enthalpy is even more negative when a standard adsorption enthalpy for oxygen of $-200 \mathrm{~kJ} \mathrm{~mol}^{-1}$ is used, which was reported by Sen and Vannice (1991) for oxygen chemisorption from the gas phase. Again, the calculated standard entropies and enthalpies may not correspond to el ementary steps.

Possible Improvements. The final model, corresponding to reaction path III, adequately describes all experimental data in the time interval between 0 and $10000 \mathrm{~s}$ for the experimental conditions listed in Table 1. Figure 8 shows a typical evolution of the fractional coverages by the adsorbed species. Due to the physisorption equilibrium that is assumed for methyl $\alpha$-Dglucopyranoside and methyl $\alpha$-D-glucuronic acid and the constant concentration in the reactor, the fractional coverages by these species are also constant. The fractional coverage of oxygen adatoms initially amounts to 1 , because for eqs 14 and 15 the approximation was made that $\theta *$ could be neglected at the conditions listed in Table 1, which as a consequence reduces the bal ance of chemisorption sites in Table 3 to $1=\theta_{0}+\theta_{\text {osub. }}$. At the conditions corresponding to Figure 8 the degree of coverage with oxygen atoms, $\theta_{\mathrm{O}}$, gradually decreases to 0.22 and the fractional coverage of subsurface oxygen, $\theta_{\text {Osub, }}$ correspondingly increases to 0.78 in $10000 \mathrm{~s}$. Due to this slow transformation, described by step 6 in Table 2 , the observed decrease of the rate is adequately described, as indicated in Figure 8a.

Although the final model adequately describes the data up to $10000 \mathrm{~s}$ for the experimental conditions listed in Table 1, the limitations of the model are revealed in the following situations: (i) extension of the oxidation period, (ii) oxidative instead of reductive startup, and (iii) recovery of the rate after a reduction following an overoxidation.

(i) Whereas it was observed that extension of the oxidation period to $100000 \mathrm{~s}$ results in a continual

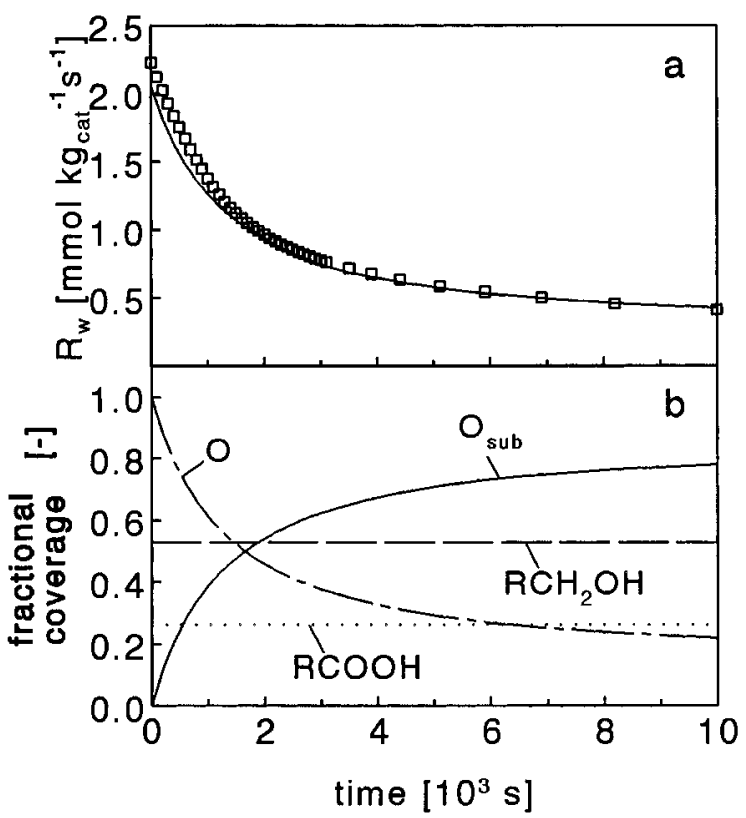

Figure 8. Typical result obtained with eqs 14 and 15 (reaction path III). (a) Specific rate of consumption of methyl $\alpha$-D-glucopyranoside, $\mathrm{R}_{\mathrm{w}}$ : symbols, experimental data; line, calculated according to eqs 14 and 15 and parameter values in Table 6. (b) Calculated fractional coverage of oxygen, $\mathrm{O}$, subsurface oxygen,

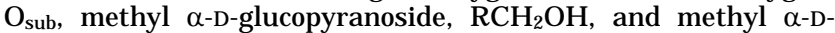
glucuronic acid, $\mathrm{RCOOH}$. Conditions were as follows: $\mathrm{pH}=8.0$, $\mathrm{P}_{2}{ }^{0}=40 \mathrm{kPa}, \mathrm{C}_{\mathrm{MGP}}=82 \mathrm{~mol} \mathrm{~m}{ }^{-3}, \mathrm{C}_{\mathrm{NaMG}}=8.8 \mathrm{~mol} \mathrm{~m}^{-3}$.

decrease of the rate, which can still be restored, the cal culated rate reaches a steady-state value after 50000 $\mathrm{s}$. This is due to the fact that the deactivation is described by a reversible step, step 6 in Table 2.

(ii) After an oxidative start-up, during which the catalyst is preoxidized in water for 2-20 h, a low initial rate is observed experimentally, which decreases even further without reaching a steady state. On the other hand the present model describes a gradual increase to a steady-state value, when starting from a fully overoxidized surface, i.e., $\theta_{\text {osub }}>0.9$.

(iii) The final model has a limited capability to describe the recovery of the rate upon intermediate reduction of the catalyst by decreasing the oxygen concentration in the liquid. Experimentally a full recovery of the rate is observed for an intermediate reduction of the catalyst for $1000 \mathrm{~s}$ as shown in Figure 1a. Upon simulation of this experiment with the nonapproximated equations for reaction path III, eqs 12 and 13 , assuming that $K_{1}$ equals to $10 \mathrm{~m}^{3} \mathrm{~s}^{-1}$ at 323 K (Schuurman et al., 1992c), the fractional coverage of subsurface oxygen decreases only with $10 \%$ in the reduction period of $1000 \mathrm{~s}$ and the calculated rate is restored only partially.

The discrepancies between the simulation results and the experimental data upon extrapolation of the modeling results to conditions outside the range that was used for the kinetic regression may result from the shortcomings of Langmuir-Hinshel wood kinetics in describing overoxidation. The assumptions underlying LangmuirHinshel wood kinetics are likely to be no longer valid for processes that may coincide with surface reconstructions (Lauterbach et al., 1994). J elemensky et al. (1996) used an approach in which the Langmuir-Hinshel wood kinetics were modified with a feedback mechanism, in which the transformation of oxygen adatoms into subsurface oxygen is strongly facilitated by the presence of subsurface oxygen and the reverse transformation of 
subsurface oxygen into oxygen adatoms is strongly inhibited by the presence of oxygen adatoms. In this way the fast transformation of subsurface oxygen into surface oxygen upon reduction in the absence of oxygen may be described more adequately. However, in the present work application of such a feedback mechanism did not lead to meaningful and statistically significant parameter estimates for any of the models that were tried. Therefore, the regression was limited to the range of conditions defined in Table 1 and the time interval between 0 and $10000 \mathrm{~s}$, in which case LangmuirHinshel wood kinetics are capable of adequately describing the overoxidation phenomena.

\section{Conclusions}

The platinum-catalyzed selective oxidation of methyl $\alpha$-D-glucopyranoside has been adequately described over a broad range of reaction conditions by a LangmuirHinshelwood type of kinetic model. The observed deactivation, which takes place on a time scale of 10000 $s$, coincides with an increase of the catalyst potential and is attributed to an extrinsic or side relaxation process in which oxygen adatoms are slowly transformed into inactive subsurface oxygen. This so-called overoxidation process is completely reversible. Deactivation due to platinum particle growth, site coverage by carbonaceous species, or metal leaching was not observed.

The most adequate description of the data is obtained when reversible physisorption of methyl $\alpha$-D-glucopyranoside and methyl $\alpha$-D-glucuronate, reversible dissociative chemisorption of oxygen and reversible formation of subsurface oxygen is assumed. The obtained rate equation can be written as the product of an initial rate and a deactivation function. The initial rate is not a function of the oxygen partial pressure. The deactivation function is given as a function of the degree of coverage by inactive subsurface oxygen. The transformation of oxygen into subsurface oxygen does not depend strongly on the oxygen partial pressure, because the platinum surface is mainly covered by oxygen at the conditions that were applied. The assessment of the Arrhenius parameters reveals that some of the steps in the proposed model are not true elementary steps. Further extension of the description of the overoxidation process is required in order to describe both the deactivation and the regeneration of the catalyst.

\section{Acknowledgment}

The financial support by the Dutch Ministry of Agriculture, Nature Management and Fisheries through its special program on Carbohydrate Oxidation, Project No. 70103, is gratefully acknowledged.

\section{Nomenclature}

$\mathrm{b}=$ parameter estimate

$\mathrm{C}=$ concentration $\left(\mathrm{mol} \mathrm{m}^{-3}\right)$

$\mathrm{C}_{\text {cat }}=$ catalyst concentration $\left(\mathrm{kg} \mathrm{m}^{-3}\right)$

$\mathrm{E}=$ potential $(\mathrm{V})$

$\mathrm{F}_{\mathrm{v}}=$ volumetric flow rate $\left(\mathrm{m}^{3} \mathrm{~s}^{-1}\right)$

$\mathrm{h}=$ Planck constant $\left(6.626 \times 10^{-34} \mathrm{~J} \mathrm{~s}\right)$

$\mathrm{H}=$ enthalpy $\left(\mathrm{mol}^{-1}\right)$

$\mathrm{k}=$ reaction rate coefficient $\left(\mathrm{s}^{-1}\right)$

$\mathrm{K}=$ equilibrium constant $\left(\mathrm{m}^{3} \mathrm{~mol}^{-1}\right)$

$\mathrm{L}=$ specific amount of surface atoms $\left(\mathrm{mol} \mathrm{kg}_{\mathrm{cat}}{ }^{-1}\right)$

$\mathrm{n}=$ number

$\mathrm{N}_{\mathrm{a}}=$ Avogadro constant $\left(6.022 \times 10^{23} \mathrm{~mol}^{-1}\right)$ $\mathrm{p}=$ pressure $(\mathrm{Pa})$

$\mathrm{R}=$ gas constant $\left(8.314 \mathrm{~J} \mathrm{~mol}^{-1} \mathrm{~K}^{-1}\right)$

$\mathrm{R}_{\mathrm{w}}=$ specific rate of consumption $\left(\mathrm{mol} \mathrm{kg}_{\mathrm{cat}}{ }^{-1} \mathrm{~s}^{-1}\right.$ )

$\mathrm{RHE}=$ reversible hydrogen electrode

$r=$ rate $\left(s^{-1}\right)$

$\mathrm{S}=$ entropy $\left(\mathrm{J} \mathrm{mol}^{-1} \mathrm{~K}^{-1}\right)$

$\mathrm{SSR}=$ sum of squared residuals

$\mathrm{T}=$ temperature $(\mathrm{K})$

$\mathrm{t}=$ time (s)

$\mathrm{W}=$ mass $(\mathrm{kg})$

$*$ site

Greek Symbols

$\theta=$ fractional coverage

$\sigma=$ stoichiometric number

$\varphi_{\text {oinact }}=$ deactivation function

Subscripts

app = apparent

avg $=$ average

cat $=$ catalyst

$\mathrm{i}=$ of $\mathrm{i}$ th class

inact $=$ inactive

$\mathrm{L}=$ liquid phase

MGP = methyl $\alpha$-D-glucopyranoside

NaMG $=$ sodium methyl $\alpha$-D-glucuronate

$\mathrm{O}=$ oxygen atom

obs $=$ observations

Oinact $=$ inactive oxygen atom

Osub = subsurface oxygen atom

$\mathrm{RCH}_{2} \mathrm{OH}=$ methyl $\alpha$-D-glucopyranoside

$\mathrm{RCOOH}=$ methyl $\alpha$-D-glucuronic acid

sub $=$ subsurface

$\mathrm{t}=$ total

$*=$ active site for chemisorption

$* \mathrm{P}=$ site for physisorption

*sub $=$ subsurface site

\section{Superscripts}

$0=$ at reactor inlet, standard, initial

$\wedge=$ calculated

\# = activation

\section{Literature Cited}

Abbadi, A.; Van Bekkum, H. Effect of pH in the Pt-Catalyzed Oxidation of D-Glucose to D-Gluconic Acid. J . Mol. Catal. A: Chem. 1995, 97, 111.

Besson, M.; Gallezot, P.; Lahmer, F.; Flèche, G.; Fuertes, P. Oxidation of Glucose on Palladium Catalysts: Particle Size and Support Effects. In Catalysis of Organic Reactions; Kosak, J. R., J ohnson, T. A., Eds.; Marcel Dekker: New York, 1994; Chemical Industries, Vol. 53, p 169.

Brönnimann, C.; Bodnar, Z.; Hug, P.; Mallat, T.; Baiker, A. Direct Oxidation of L-Sorbose to 2-K eto-L-gulonic Acid with M olecular Oxygen on Platinum- and Palladium-Based Catalysts. J . Catal. 1994, 150, 199.

De Bruijn, F. A. The Platinum Catalyzed Oxidative Dehydrogenation of Aqueous Alcohols: An Investigation by Electrochemical Methods. Ph.D. Thesis, Eindhoven University of Technology: Eindhoven, 1996.

Dijkgraaf, P. J . M.; Rijk, M. J . M.; Meuldijk, J .; Van der Wiele, K. Deactivation of Platinum Catalysts by Oxygen. 1. Kinetics of Catalyst Deactivation. J . Catal. 1988a, 112, 329.

Dijkgraaf, P. J . M.; Duisters, H. A. M.; Kuster, B. F. M.; Van der Wiele, K. Deactivation of Platinum Catalysts by Oxygen. 2. Nature of the Catalyst Deactivation. J . Catal. 1988b, 112, 337.

Dirkx, J . M. H.; Van der Baan, H. S. The Oxidation of Glucose with Platinum on Carbon as Catalyst. J . Catal. 1981a, 67, 1.

Dirkx, J . M. H.; Van der Baan, H. S. The Oxidation of Gluconic Acid with Platinum on Carbon as Catalyst. J. Catal. 1981b, 67, 14.

Everett, D. H. The Thermodynamics of Adsorption: Part II.Thermodynamics of Monolayers on Solids. Trans. Faraday Soc. 1950, 46, 942. 
Froment, G. F.; Bischoff, K. B. Chemical Reactor Analysis and Design; Wiley: New York, 1990.

Heyns, K.; Paulsen, H. Selective Catalytic Oxidation of Carbohydrates, Employing Platinum Catalysts. Adv. Carbohydr. Chem. 1962, 17, 169.

J elemensky, L.; Kuster, B. F. M; Marin, G. B. Kinetic Modelling of Multiple Steady-States for the Oxidation of Aqueous Ethanol with Oxygen on a Carbon Supported Platinum Catalyst. Chem. Eng. Sci. 1996, 51, 1767.

J elemensky, L.; Kuster, B. F. M; Marin, G. B. Relaxation Processes during the Selective Oxidation of Aqueous Ethanol with Oxygen on a Platinum Catalyst. Ind. Eng. Chem. Res., in press.

Khan, M. I. A.; Miwa, Y.; Morita, S.; Okado, J . Liquid-phase Oxidation of Ethylene Glycol on a Pt/C Catalyst. II. Kinetic Studies. Chem. Pharm. Bull. 1983, 31, 1827.

Kieboom, A. P. G.; Van Bekkum, H. Aspects of the Chemical Conversion of Glucose. Recl. Trav. Chim. Pays-Bas 1984, 103, 1 .

Kittrell, J . R. Mathematical Modeling of Chemical Reactions. In Advances in Chemical Engineering; Drew, T. B., et al., Eds.; Academic Press: New York, 1970; p.97.

Laidler, K.J . Chemical Kinetics; Harper \& Row, Publishers: New York, 1987.

Lauterbach, J .; Asakura, K.; Rotermond, H. H. Subsurface Oxygen on $\mathrm{Pt}(100)$ : Kinetics of the Transition from Chemisorbed to Subsurface State and its Reaction with $\mathrm{CO}, \mathrm{H}_{2}$ and $\mathrm{O}_{2}$. Surf. Sci. 1994, 313, 52.

Mallat, T.; Baiker, A.; Botz, L. Liquid-phase Oxidation of 1-Methoxy-2-propanol with Air. III. Chemical Deactivation and Oxygen Poisoning of Platinum Catalysts. Appl. Catal., A 1992, 86, 147.

Mallat, T.; Bodnar, Z.; Baiker, A. Partial Oxidation in Water-Insoluble Alcohols over Bi-promoted Pt on Alumina. Electrochemical Characterization of the Catalyst in its Working State. In Heterogeneous Catalysis and Fine Chemicals III; Guisnet, M., et al., Eds.; Elsevier: Amsterdam, 1993; p 377.

Mallat, T.; Baiker, A., Oxidation of Alcohols with Molecular Oxygen on Platinum Metal Catalysts in Aqueous Solutions. Catal. Today 1994, 19, 247.

Mallat, T.; Baiker, A. Catalyst Potential: a Key for Controlling Alcohol Oxidation in Multiphase Reactors. Catal. Today 1995, 24, 143.

Marquardt, D. W. An Algorithm for Least-Squares Estimation of Nonlinear Parameters. J . Soc. Ind. Appl. Math. 1963, 11, 431.

Nondek, L.; Ždárová, D.; Málek, J .; Chvalovský, V. Conversion of 2,3:4,6-di-o-I sopropylidene-L-sorbose to 2,3:4,6-di-o-I sopropylidene-2-keto-L-gulonic acid by Catalytic Oxidation with Oxygen on Platinum. Collect. Czech. Chem. Commun. 1982, 47, 1121.

Parsons, R.; VanderNoot, T. The Oxidation of Small Organic Molecules. A Survey of Recent Fuel Cell Related Research. J . Electroanal. Chem. 1988, 257, 9.

Peukert, M.; Coenen, F. P.; Bonzel, H. P. XPS Study of the Electrochemical Surface Oxidation of Platinum in $1 \mathrm{~N} \mathrm{H}_{2} \mathrm{SO}_{4}$ Acid Electrolyte. Electrochim. Acta 1984, 29, 1305.

Richard, D.; Gallezot, P. Preparation of Highly Dispersed, Carbon Supported, Platinum Catalysts. In Preparation of Catalysts IV;
Delmon, B., Grange, P., J acobs, P. A., Poncelet, G., Eds.; Elsevier: Amsterdam, 1987; Studies in Surface Science and Catalysis, Vol. 31, p 71.

Röper, H.; Koch, H. New Carbohydrate Derivatives from Biotechnical and Chemical Processes. Starch/ Stärke 1988, 40, 453.

Schuurman, Y.; Kuster, B. F. M.; Van der Wiele, K.; Marin, G. B. Selective Oxidation of Methyl $\alpha$-D-Glucoside on Carbon Supported Platinum. III. Catalyst Deactivation. Appl. Catal., A 1992a, 89, 47.

Schuurman, Y.; Kuster, B. F. M.; Van der Wiele, K.; Marin, G. B. The Selective Oxidation of Methyl $\alpha$-D-Glucoside on a Carbon Supported Pt Catalyst. In New Developments in Selective Oxidation by Heterogeneous Catalysis; Ruis, P., Delmon, B., Eds.; Elsevier: Amsterdam, 1992b; Studies in Surface Science and Catalysis, Vol. 72, p 43.

Schuurman, Y.; Kuster, B. F. M.; Van der Wiele, K.; Marin, G. B. Selective Oxidation of Methyl $\alpha$-D-Glucoside on Carbon Supported Platinum. II. Assessment of the Arrhenius and Langmuir Parameters. Appl. Catal., A 1992c, 89, 31.

Sen, B.; Vannice, M. A. Enthalpy Changes during $\mathrm{O}_{2}$ Adsorption and $\mathrm{H}_{2}$ Titration of Adsorbed Oxygen on Platinum. J . Catal. 1991, 129, 31.

Temkin, M. I. The Kinetics of Steady-State Complex Reactions. Int. Chem. Eng. 1971, 11, 709.

Temkin, M. I. Relaxation Rate of Two-stage Catalytic Reaction. Kinet. Catal. 1976, 17, 945.

Van Bekkum, H. Studies on Selective Carbohydrate Oxidation. In Carbohydrates as Raw Materials; Lichtenthaler, F. W., Ed.; VCH: Weinheim, 1991; p 289.

Van Dam, H. E.; Wisse, L. J .; Van Bekkum, H. Platinum/Carbon Oxidation Catalysts. VIII. Selecting a Metal for Liquid-Phase Alcohol Oxidations. Appl. Catal. 1990, 61, 187.

Van den Tillaart, J . A. A.; Kuster, B. F. M.; Marin, G. B. Oxidative Dehydrogenation of Aqueous Ethanol on a Carbon Supported Platinum Catalyst. Appl. Catal., A 1994, 120, 127.

Vleeming, J . H.; De Bruijn, F. A.; Kuster, B. F. M.; Marin, G. B. Deactivation of Carbon-supported Platinum Catalysts during Oxidation in Aqueous Media. In Catalyst Deactivation 1994; Delmon, B., Froment, G. F., Eds.; Elsevier: Amsterdam, 1994; Studies in Surface Science and Catalysis, Vol. 88, p 467.

Vleeming, J. H.; Kuster, B. F. M.; Marin, G. B.; Oudet, F.; Courtine, P. Graphite-Supported Platinum Catalyst: Effects of Gas and Aqueous Phase Treatments. J . Catal. 1997, 166, 148.

Received for review December 2, 1996 Revised manuscript received April 25, 1997 Accepted May 2, $1997^{\otimes}$

IE9607659

\footnotetext{
${ }^{\otimes}$ Abstract published in Advance ACS Abstracts, J uly 1,
} 